\title{
Expression of Kv1 Potassium Channels in Mouse Hippocampal Primary Cultures: Development and Activity-Dependent Regulation
}

\author{
Gisela Grosse, Andreas Draguhn, Lysann Höhne, Rosemarie Tapp, Ruediger W. Veh, and \\ Gudrun Ahnert-Hilger
}

1/nstitut für Anatomie der Charité, Humboldt-Universität zu Berlin, 10115 Berlin, Germany

\begin{abstract}
Excitability and discharge behavior of neurons depends on the highly variable expression pattern of voltage-dependent potassium (Kv) channels throughout the nervous system. To learn more about distribution, development, and activity-dependent regulation of $\mathrm{Kv}$ channel subunit expression in the rodent hippocampus, we studied the protein expression of members of the Kv1 subfamily in mouse hippocampus in situ and in primary cultures.

In adult hippocampus, Kv1 (1-6) channel $\alpha$-subunits were present, whereas at postnatal day 2, none of these proteins could be detected in CA1-CA3 and dentate gyrus. Kv1.1 was the first channel to be observed at postnatal day 6 . The delayed postnatal expression and most of the subcellular distribution observed in hippocampal sections were mimicked by cultured hippocampal neurons in which Kv channels appeared only after 10 days in vitro. This developmental upregulation was paralleled by a dramatic increase in total $\mathrm{K}^{+}$current, as well as an elevated GABA release in the presence of 4-aminopyridine.
\end{abstract}

Thus, the developmental profile, subcellular localization, and functionality of Kv1 channels in primary culture of hippocampus closely resembles the in situ situation.

Impairing secretion by clostridial neurotoxins or blocking activity by tetrodotoxin inhibited the expression of Kv1.1, $\mathrm{Kv1.2}$, and Kv1.4, whereas the other Kv1 channels still appeared. This activity-dependent depression was only observed before the initial appearance of the respective channels and lost after they had been expressed.

Our data show that hippocampal neurons in culture are a convenient model to study the developmental expression and regulation of $\mathrm{Kv} 1$ channels. The ontogenetic regulation and the activity-dependent expression of Kv1.1, Kv1.2, and Kv1.4 indicate that neuronal activity plays a crucial role for the development of the mature Kv channel pattern in hippocampal neurons.

Key words: Kv1 channels; primary culture of hippocampus; subcellular distribution; developmental expression; activitydependent regulation; clostridial neurotoxins; tetrodotoxin
A great variety of voltage-dependent potassium channels (Kv channels) are involved in the regulation of neuronal excitability and synaptic transmission. They contribute to action potential repolarization and influence the form and frequency of action potentials. Six families of $\mathrm{Kv}$ channels have been identified in mammalian tissue that are homologous to the respective Drosophila genes, including the Shaker-related Kv1 family (Roeper and Pongs, 1996). Besides being divided into subfamilies based on sequence homologies, Kv channels can be classified according to their biophysical behavior (Hille, 1992).

Members of the Kv1 family mostly represent slowly activating and inactivating delayed rectifier channels $\left(I_{\mathrm{K}}\right)$, with the exception of Kv1.4, which is a fast-inactivating A-type channel $\left(I_{\mathrm{A}}\right)$. Functional Kv channels are formed by four subunits that assemble in the plasma membrane. The heterogeneity of $\mathrm{Kv}$ channels is complicated by the fact that the different subunits encoded within the Kv1 Shaker family may coassemble to heterotetramers, resulting in channels of mixed functional properties (Christie et al., 1990; Isacoff et al., 1990; Ruppertsberg et al., 1990; Covarrubias et

\footnotetext{
Received Aug. 23, 1999; revised Dec. 6, 1999; accepted Dec. 14, 1999.

This work was supported by the Deutsche Forschungsgemeinschaft and the Stiftung Verum. We are indebted to Evelyn Heuckendorf, Sabine Lewandowski, and Dore Wachenschwanz for expert technical assistance, Dr. Uwe Heinemann for valuable suggestions, and Anja Becher for critically reading this manuscript.

Correspondence should be addressed to Gudrun Ahnert-Hilger, Institut für Anatomie der Charité, Humboldt-Universität zu Berlin, Philippstrasse 12, 10115 Berlin, Germany. E-mail: gudrun.ahnert@charite.de.

This article contains part of the thesis (medical doctor) of L. Höhne

Copyright (C) 2000 Society for Neuroscience $0270-6474 / 00 / 201869-14 \$ 15.00 / 0$
}

al., 1991) that appear to be also relevant in adult nervous system (Sheng et al., 1993; Wang et al., 1993). Forming of heterotetramers is restricted, however, to members of the same family and does not occur among different subclasses, e.g., between subunits of the Kv1, Kv2, Kv3, or Kv4 family (Covarrubias et al., 1991; Salkoff et al., 1992). In addition, accessory $\beta$-subunits can markedly alter channel properties (Robertson, 1997). Besides the great variety of genes responsible for $\mathrm{Kv}$ channel expression, differential regional and subcellular localization in the CNS further add to functional diversity (Sheng et al., 1992; Wang et al., 1994; Veh et al., 1995; Rhodes et al., 1997). These interneuronal and intraneuronal variances may enable neurons to regulate postsynaptic integrative responses in somatodendritic compartments or to modulate presynaptic action potential frequency and waveform in axons and terminals. The resulting variability is one of the probable mechanisms by which neurons may gain plasticity required for learning processes or adapt to environmental changes in the course of their development.

So far, little data exists concerning the developmental properties of $\mathrm{Kv}$ channels in brain in situ and in vitro (Klee et al., 1995; Maletic-Savatic et al., 1995). Hippocampal neurons are highly plastic in their excitability both in adult brain and during neuronal development. Fetal hippocampal neurons can be easily isolated and grown in culture for several weeks in which they mimic some aspects of the in vivo ontogenesis, such as the expression of $\mathrm{GABA}_{\mathrm{A}}$ receptors (Killisch et al., 1991), various synaptic contacts (Fletcher et al., 1994) including mossy fibers boutons between granule cells and pyramidal dendrites 

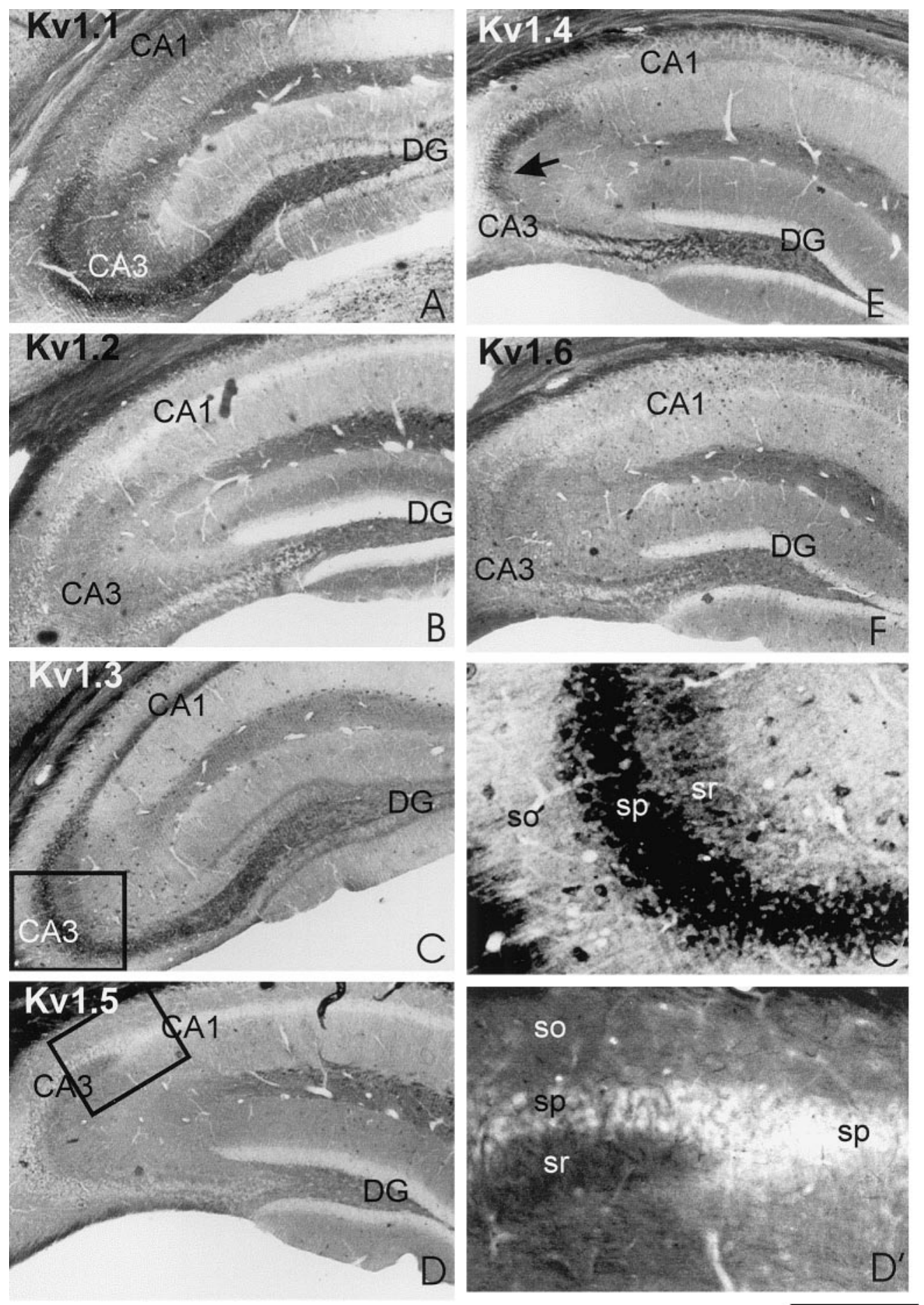

Figure 1. Differential localization of Kv1 channel subtypes in mouse hippocampus. $a$, Coronal vibratome sections (50 $\mu \mathrm{m})$ of hippocampi from adult mice were incubated with antisera against $\operatorname{Kv1} 1(A), \operatorname{Kv1} 2(B), \operatorname{Kv1} 3\left(C, C^{\prime}\right), \operatorname{Kv} 1.4(E), \operatorname{Kv} 1.5\left(D, D^{\prime}\right)$, or $\operatorname{Kv1.6}(F)$ as outlined in Materials and Methods. The arrow in $E$ marks the intense staining of the mossy fibers by the antiserum against Kv1.4. The differential staining in the various layers of hippocampal CA3 region are outlined in detail for Kv1.3 (compare $C$ with $C^{\prime}$ ). Kv1.3 occurs in high amounts in stratum pyramidale ( $s p$ ), whereas lesser amounts are present in stratum radiatum $(s r)$, and almost no channel protein is found in stratum oriens (so). Kv1.5 appears to be localized to stratum pyramidale $(s p)$ of CA3 and to a lesser extent of CA1 in which it preferentially occurs in the neuropil as given in detail in $D^{\prime}$. Scale bar: $A-F$, $500 \mu \mathrm{m}$; $C^{\prime}, D^{\prime}, 130 \mu \mathrm{m} . b$, Coronal vibratome sections $(70 \mu \mathrm{m})$ of hippocampi from mice pups of postnatal day 2 or 6 were incubated with antisera against Kv1.1 $(A, B), \operatorname{Kv1.2}(C), \operatorname{Kv1.3}(D), \operatorname{Kv1.4}(E), \operatorname{Kv1.5}(F)$, or $\operatorname{Kv1.6}(G)$ or without the first antiserum $(H)$ as outlined in Materials and Methods. Kv1.1 is the earliest channel to be detected in some pyramidal neurons of CA3 and dentate gyrus at postnatal day $6(B)$, which is clearly distinguishable when comparing with the respective control section $(H)$. However, no specific immunoreactivity can be observed with the Kv1.1 antiserum at postnatal day 2 (compare $A$ with $H$ ). The incubation of postnatal day 6 hippocampal section with $\operatorname{Kv1.2~to~} \operatorname{Kv} 1.6(C-G)$ only gives an unspecific staining closely resembling the one of the control section $(H)$. 

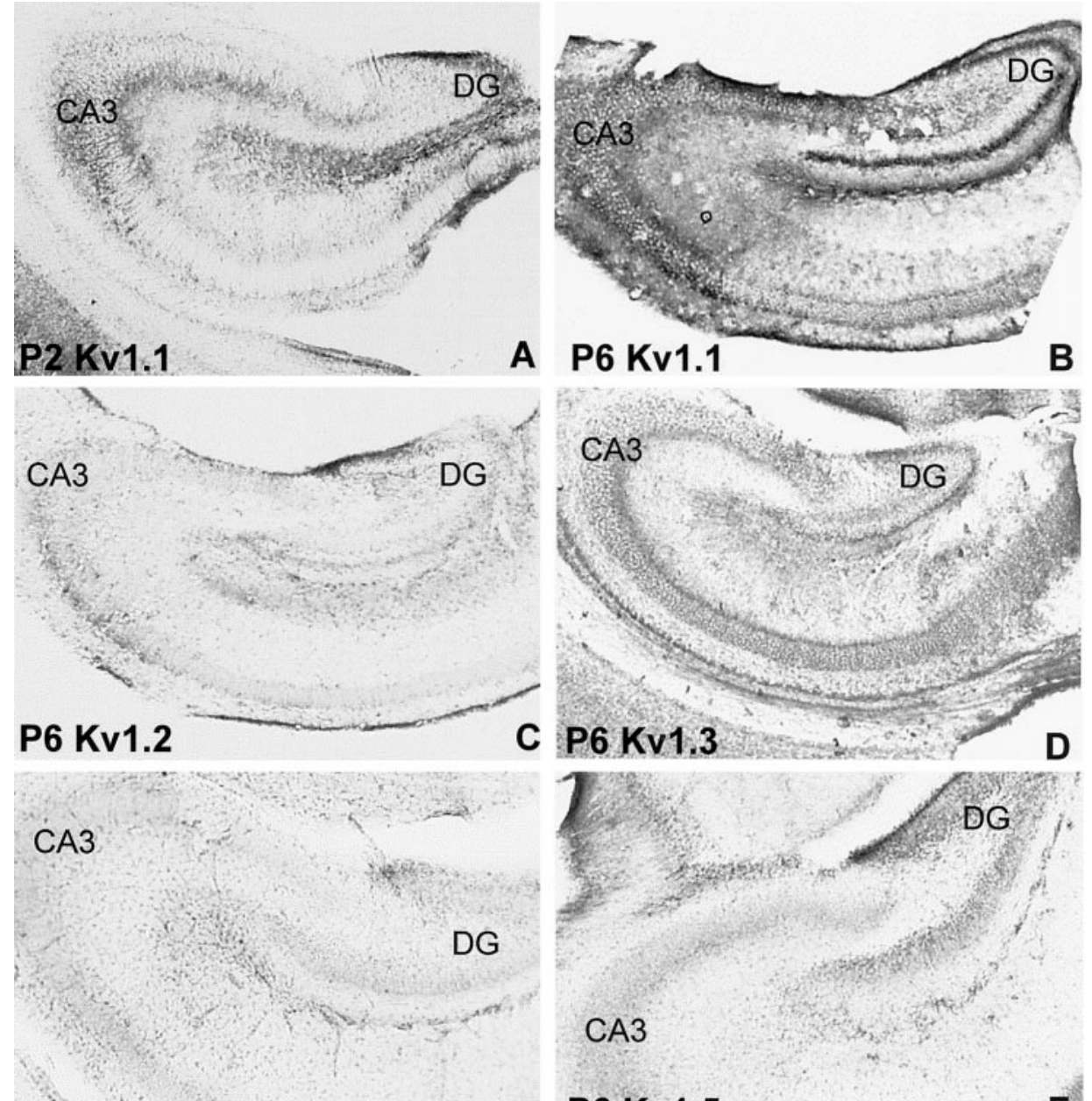

P6 Kv1.4

C $\mathrm{P} 6 \mathrm{Kv} 1.3$

B

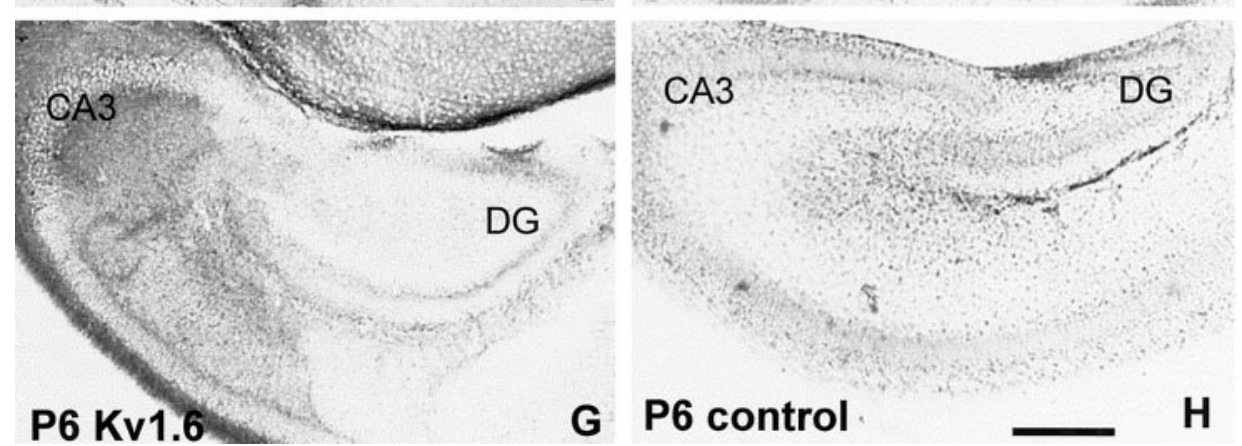

Figure 1 continued

(Große et al., 1998), and the expression of certain $\mathrm{K}^{+}$channels (Ficker and Heinemann, 1992; Klee et al., 1995). As far as the in situ pattern is maintained in cell cultures, they comprise ideal systems for the analysis of mechanisms regulating the expression of ion channels.

Here, we show that neurons of fetal mouse hippocampus express most of the Kv1 channel $\alpha$-subunits in culture in a period of time and with a subcellular distribution almost comparable with their in vivo development. Sustained block of synaptic exocytosis by clostridial neurotoxins or block of action potentials by tetrodotoxin suppressed the expression of certain Kv1 subunits, whereas other members of this family seemed to be expressed independently of activity.

\section{MATERIALS AND METHODS}

Antibodies and toxins. Polyclonal antisera against pGEX-fusion proteins with the $\alpha$-subunits of Kv1.1-Kv1.6 were raised in rabbits and immunopurified as described previously (Rettig et al., 1992; Rhodes et al., 1995; Veh et al., 1995). Characterization of the specificity of all antisera, especially for immunocytochemical applications, has been performed in rat brain tissue (Veh et al., 1995). Monoclonal antibodies against synaptobrevin and synaptosomal-associated protein of $25 \mathrm{kDa}$ (SNAP-25) were generous gifts from R. Jahn (Max-Planck-Institut für Biophysikalische Chemie, Göttingen, Germany). A monoclonal antibody against microtubule associated protein 2 (MAP2) was purchased from Boehringer Mannheim (Mannheim, Germany).

Immunocytochemical detection was performed with biotinylated goat anti-rabbit IgG using the ABC Vectastain Elite Kit obtained from Vector Laboratories (Wiesbaden, Germany). In double immunofluorescence 
labeling experiments, monoclonal antibodies were detected with antimouse $\operatorname{IgG}$ coupled to $\mathrm{Cy} 2$ and rabbit antisera with a biotinylated anti-rabbit $\mathrm{IgG}$ visualized by avidin coupled to Texas Red obtained from Jackson ImmunoResearch (West Grove, PA), Dianova (Hamburg, Germany), or Vector Laboratories, respectively. For immunoreplica analysis, peroxidase-labeled goat anti-rabbit IgG, purchased from Dianova, was used and developed by diaminobenzidine and $\mathrm{H}_{2} \mathrm{O}_{2}$.

For electron microscopy, goat anti-rabbit $\mathrm{IgG}$ coupled to $1 \mathrm{~nm}$ of gold and the silver enhancement IntenSE-M kit were purchased from Amersham Pharmacia Biotech (Freiburg, Germany). Carboxymethylated bovine serum albumin-C (BSA-C) and normal goat serum were obtained from Aurion (Wageningen, Germany) and Pan Systems (Aidenbach, Germany), respectively.

Clostridial neurotoxins, tetanus toxin (TeNt), as well as botulinum neurotoxin type $\mathrm{A}(\mathrm{BoNt} / \mathrm{A})$ and $\mathrm{B}(\mathrm{BoNt} / \mathrm{B})$ were kindly supplied by $\mathrm{H}$. Bigalke (Institut für Toxikologie der Medizinischen Hochschule, Hannover, Germany). Tetrodotoxin (TTX) was purchased from Boehringer Mannheim. All other chemicals were of the purest degree commercially available.

Primary culture of mouse hippocampal neurons. Hippocampal neurons were prepared from 17-d-old fetal Naval Medical Research Institute (NMRI) mice as described previously (Große et al., 1998). Briefly, dissected hippocampi were mechanically dissociated, spun down, and resuspended in Eagle's medium (Life Technologies, Berlin, Germany) supplemented with insulin $(10 \mu \mathrm{g} / \mathrm{ml})$, apo-transferrin $(0.1 \mathrm{mg} / \mathrm{ml})$, aprotinin $(1 \mu \mathrm{g} / \mathrm{ml})$, bovine serum albumin $(1 \mathrm{mg} / \mathrm{ml})$, sodium selenite $(30$ $\mathrm{nM}), 3,3^{\prime}, 5$-triiodo-thyronine $(0.1 \mathrm{~nm})$, and glucose $(0.25 \%)$. All ingredients were obtained from Sigma (München, Germany). The cell suspension was seeded on poly-D-lysine-coated plastic dishes (Nunc, Wiesbaden, Germany) or coverslips at a density of $1 \times 10^{5} / \mathrm{cm}^{2}$, and neurons were cultivated up to 21 days in vitro (DIV) in an humidified atmosphere with $10 \% \mathrm{CO}_{2}$.

Immunocytochemistry. Deeply anesthetized NMRI mice were cardially perfused by a fixative containing $4 \%$ formalin, $0.05 \%$ glutaraldehyde, and $0.2 \%$ picric acid dissolved in $0.1 \mathrm{M}$ phosphate buffer, $\mathrm{pH} 7.4$, for 30 min. The fixative was removed by subsequently perfusing the animals with $0.15 \mathrm{M}$ sucrose in $0.1 \mathrm{M}$ phosphate buffer, $\mathrm{pH}$ 7.4. Immunocytochemistry was performed using $50 \mu \mathrm{m}$ vibratome sections by the avidin-biotin detection system as described previously (Veh et al., 1995). The following dilutions of the affinity-purified antisera were used: Kv1.1, 1:500; Kv1.2, 1:1000; Kv1.3, 1:30; Kv1.4, 1:500; Kv1.5, 1:20; and Kv1.6, 1:1000.

Hippocampi of mice pups were freshly removed and placed in ice-cold PBS. They were fixed in $4 \%$ formalin dissolved in $0.1 \mathrm{~m}$ phosphate buffer for $1 \mathrm{hr}$ on ice and $2 \mathrm{hr}$ at room temperature. Vibratome sections $(70 \mu \mathrm{m})$ were further processed for immunocytochemistry using the protocol given above.

Primary hippocampal neurons were fixed at various DIV for $30 \mathrm{~min}$ in $4 \%$ formalin dissolved in $0.1 \mathrm{M}$ phosphate buffer, $\mathrm{pH}$ 7.4. Fixed cells were treated with $1 \%$ sodium borohydride in PBS for 15 min and subsequently permeabilized for $30 \mathrm{~min}$ at room temperature using $0.3 \%$ Triton $\mathrm{X}-100$ dissolved in PBS. Incubation with primary antisera was performed at $4^{\circ} \mathrm{C}$ for $36 \mathrm{hr}$. The cells were washed with PBS and incubated with a biotinylated goat anti-rabbit IgG for another $24 \mathrm{hr}$ at $4^{\circ} \mathrm{C}$. The biotinylated secondary antibody was complexed with avidin-conjugated to horse radish peroxidase (ABC, Vectastain Elite, 1:1000 obtained from Vector Laboratories. Peroxidase activity was visualized with diaminobenzidine using a protocol given previously (Veh et al., 1995; Laube et al., 1996).

Electron microscopy. Hippocampal neurons cultivated for at least 20 DIV were fixed in $1.5 \%$ glutaraldehyde dissolved in $0.1 \mathrm{M}$ cacodylate buffer, $\mathrm{pH} 7.2(\mathrm{NaOH})$ for $60 \mathrm{~min}$ at room temperature. Cultures were rinsed with ice-cold PBS [140 $\mathrm{mm} \mathrm{NaCl}$ and $50 \mathrm{~mm}$ phosphate (sodium salt), $\mathrm{pH} 7.4$ ) containing $10 \%$ methanol and $0.03 \% \mathrm{H}_{2} \mathrm{O}_{2}$ for $5 \mathrm{~min}$, followed by three washings with PBS. Cells were permeabilized with $0.05 \%$ saponin dissolved in HBSS (Sigma) for $10 \mathrm{~min}$ at room temperature, washed three times with PBS, and preincubated for $1 \mathrm{hr}$ at room temperature with $2 \%$ normal goat serum dissolved in PBS supplemented with $0.05 \%$ saponin and $0.1 \%$ sodium azide. The cultures were incubated for $12 \mathrm{hr}$ at $4^{\circ} \mathrm{C}$ with anti-Kv1.2 (final dilution of $1: 1000$ ) diluted in the preincubation solution (see above). The antiserum was removed, and cultures were washed repeatedly with PBS, followed by an incubation with $0.2 \%$ bovine serum albumin dissolved in PBS for $1 \mathrm{hr}$ at room temperature. Then, cultures were incubated for $24 \mathrm{hr}$ at $4^{\circ} \mathrm{C}$ with a mixture containing PBS, goat anti-rabbit IgG coupled to $1 \mathrm{~nm}$ of gold (1:50 final dilution), sodium azide $(0.1 \%)$, BSA-C $(0.1 \%)$, Tween 20 $(0.1 \%)$, and saponin $(0.1 \%)$. The incubation was stopped by several washes in PBS supplemented with $0.05 \%$ Tween, and cultures were post-fixed by $2 \%$ glutaraldehyde, followed by silver enhancing for $30-60$ min at room temperature in the dark using the IntenSE-M kit. Silver grains were stabilized by gold toning for $10 \mathrm{~min}$ at $4^{\circ} \mathrm{C}$, and membranes were marked by incubating with $1 \% \mathrm{OsO}_{4}$ for $30 \mathrm{~min}$ at room temperature, followed by dehydration and embedding in Epon. Individual pyramidal neurons were selected for ultrastructural analysis. Ultrathin sections cut parallel to the cell layer were post-stained with $4 \%$ uranyl acetate containing $0.2 \%$ lead citrate. Sections were examined by a Zeiss (Oberkochen, Germany) 900 electron microscope.

Immunoreplica analysis. Neurons were harvested at 18-21 DIV and homogenized, and the protein content was determined using the BCA detection system. The homogenate was spun down, and the pellet was dissolved in Laemmli's buffer. SDS-PAGE and immunoblotting was performed as described previously (Becher et al., 1999). Transferred proteins were incubated with antibodies against the various Kv1 channel proteins or the SNAP receptor proteins, followed by an incubation with secondary antibodies coupled to horse radish peroxidase and developed using diaminobenzidine as substrate.

Patch-clamp recordings. For measurements of voltage-dependent $\mathrm{K}^{+}$ currents, cultured cells at 8-24 DIV were transferred onto the stage of an upright microscope and continuously superfused with extracellular solution containing (in mM): $\mathrm{NaCl} 130, \mathrm{KCl} 3, \mathrm{CaCl}_{2} 2, \mathrm{MgCl}_{2}$ 1, HEPES 10 , and glucose $25, \mathrm{pH} 7.3$. Somatic whole-cell patch-clamp recordings (Hamill et al., 1981) were performed with glass electrodes of 3-5 $\mathrm{M} \Omega$ resistance filled with (in $\mathrm{mM}$ ): $\mathrm{KCl} 140, \mathrm{CaCl}_{2} 1, \mathrm{MgCl}_{2}$ 2, EGTA 11, and HEPES 10, pH 7.2. A switched single-electrode voltage-clamp amplifier (SEC 05; NPI Electronics, Tamm, Germany) was used to reduce series resistance errors. Data were sampled and stored on a personal computer using the TIDA software and interface (HEKA Elektronik, Lambrecht, Germany). Cells were voltage-clamped at $-50 \mathrm{mV}$ in the presence of 1 $\mu \mathrm{M}$ TTX (Sigma), and voltage-gated currents were elicited by voltage steps from -70 to $+50 \mathrm{mV}$ with $10 \mathrm{mV}$ increment with and without a hyperpolarizing prepulse to $-120 \mathrm{mV}(150 \mathrm{msec})$. For analysis, maximal current amplitudes were measured after leak subtraction and were normalized to the membrane capacitance, which was estimated from the charging time constant after hyperpolarizing current injection in currentclamp recording $\left[\tau=C^{*} R ; r=d U / d I\right.$, where $\tau$ is the fitted charging time constant in milliseconds, $R$ is the membrane resistance calculated from the steady-state voltage hyperpolarization $(d U)$ after a stepwise current injection $(d I)$ of $-20 \mathrm{pA}$ ] (Ficker and Heinemann, 1992).

$\left[{ }^{3} H\right] G A B A$ secretion. Cultures were preloaded with $\left[{ }^{3} \mathrm{H}\right] \mathrm{GABA}(\mathrm{Am}-$ ersham Pharmacia Biotech) as given previously (Ahnert-Hilger et al., 1996). They were washed three times with Krebs'-Ringer's-HEPES buffer containing (in mM) : $\mathrm{NaCl} 130, \mathrm{KCl} 4.7, \mathrm{MgSO}_{4} 1.2, \mathrm{CaCl}_{2} 2.5$, glucose 11, and HEPES 10, pH 7.4 (KR-HEPES buffer) and preincubated for $10 \mathrm{~min}$ at $37^{\circ} \mathrm{C}$ in KR-HEPES buffer containing $0.1 \%$ BSA. The preincubation solution was removed, and cultures were stimulated for $5 \mathrm{~min}$ at $37^{\circ} \mathrm{C}$ by increasing the $\mathrm{K}^{+}$concentration to $25 \mathrm{~mm}$ in either the absence or presence of $0.5 \mathrm{~mm}$ 4-aminopyridine (4-AP). $\left[{ }^{3} \mathrm{H}\right] \mathrm{GABA}$ was measured in the supernatant and in the cells after dissolving them in Triton X-100 $(0.4 \%)$. Release is given as the percent of $\left[{ }^{3} \mathrm{H}\right] \mathrm{GABA}$ content present at the beginning of stimulation.

\section{RESULTS}

\section{Developmental expression of Kv1.1-Kv1.6 in hippocampal neurons in situ}

The regional and subcellular distribution of Kv1.1-Kv1.6 channel subunits in mouse hippocampus was analyzed using sections obtained from adult and young (postnatal days 2-6) mice. In the adult hippocampus, all potassium channels were found to be expressed in the stratum radiatum of hippocampal CA areas (Fig. $1 a, A-F$ ). Kv1.1 (Fig. $1 a, A)$ and Kv1.2 and Kv1.6 (Fig. $1 a, B$ and $F$, respectively) could be detected also in stratum oriens, whereas Kv1.3 (Fig. $1 a, C, C^{\prime}$ ), Kv1.4, and Kv1.5 (Fig. $1 a, D, D^{\prime}, E$, respectively) were absent in this hippocampal layer. These regional differences are exemplified for Kv1.3 in detail (Fig. 1a, $C^{\prime}$ ). In the $\mathrm{CA} 3$ region (Fig. $1 a, C^{\prime}$ ), very high amounts of Kv1.3 were found in stratum pyramidale $(s p)$ and smaller amounts in the stratum radiatum $(s r)$, whereas in stratum oriens (so) almost no Kv1.3 $\alpha$-subunit was observed. 

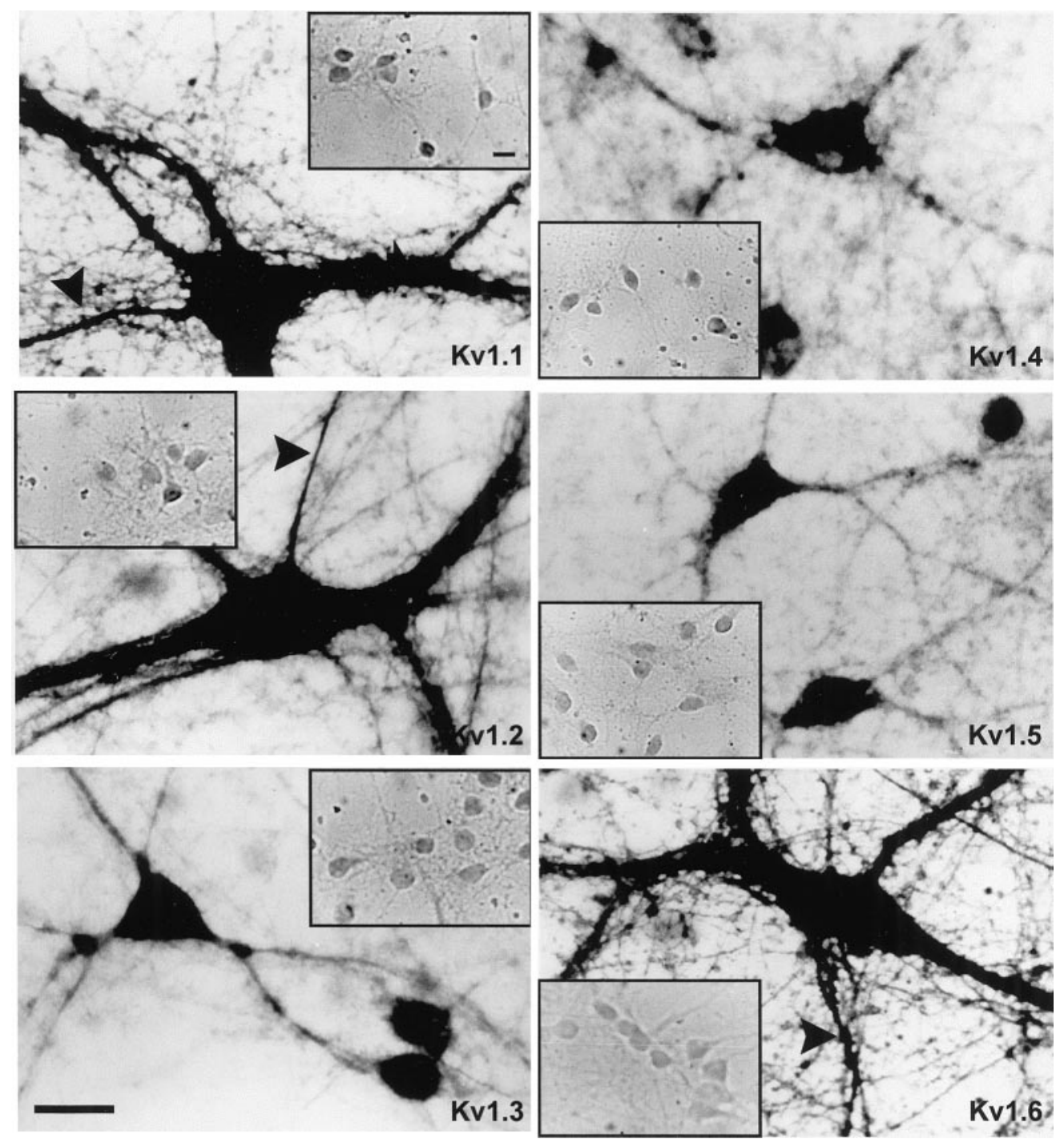

Figure 2. Expression of Kv1 channel proteins in developing neurons in primary cultures. Hippocampal neurons cultivated for $18 \mathrm{~d}$ (18 DIV) were incubated with the antisera against Kv1.1-Kv1.6 (large panels). All Kv1 channel $\alpha$-subunits are present in the somatodendritic compartment of pyramidal neurons. Kv1.1, Kv1.2, and Kv1.6 were also detected in axons, as indicated by the arrowheads. After 6 DIV, none of the Kv1 channel proteins showed up in the neuronal cultures (insets) analyzed by phase contrast. Scale bars, $20 \mu \mathrm{m}$.

Kv1.2 was expressed differently in the inner middle and upper third of the molecular layer of mouse dentate gyrus (Fig. 1a,B). A less differentiated expression in these three sublayers could be also observed for Kv1.1 (Fig. 1a, A) (Wang et al., 1994). Previously reported patterns for Kv1.1, Kv1.2, Kv1.4, and Kv1.6 in the molecular layer of rat dentate gyrus exhibited a more or less differentiated staining in these three sublayers (Veh et al., 1995; Rhodes et al., 1997). In addition in mouse hippocampus, Kv1.1 was found in the perikarya of pyramidal neurons and granule cells (Fig. 1a, A), paralleling observations by in situ hybridization (Wang et al., 1994), but did not show up in the respective rat perikarya (Rhodes et al., 1997). The opposite is true when comparing the perikaryal staining for Kv1.6, which appeared in rat perikarya (Rhodes et al., 1997) but was absent in mouse (Fig. 1a, $E)$. These differences may be attributed to species variations in the amount of expression between mouse and rat. The in vivo distribution, however, clearly indicates that, in adult mouse hippocampal pyramidal neurons, all Kv1 channel $\alpha$-subunits are present in somatodendritic compartments, whereas Kv1.1, Kv1.2, and Kv1.6 appear to occur also in axonal compartments.
Whereas expression of Kv1.4 in somatodendritic compartments of pyramidal neurons was rather weak (Fig. 1a,E), high amounts of this Kv1 channel subunit were detected in the mossy fibers (Fig. $1 a, E$, arrow). The granule cell bodies from which these axons originate, however, remained unstained (Fig. 1a, E; see also Fig. $3 B$ ), as also found for the rat (Veh et al., 1995; Rhodes et al., 1997). These findings suggest that Kv1.4 is differentially sorted to either a somatodendritic compartment in pyramidal neurons or axons in granule cells. The observed regional and subcellular distribution in mouse hippocampus mostly resembles that reported previously for rat hippocampus (Sheng et al., 1992, 1993; Maletic-Savatic et al., 1995; Veh et al., 1995; Smart et al., 1998).

When looking at the developmental expression in situ, it turned out that Kv1.1-Kv1.6 channel subunits in hippocampal neurons occurred rather late during neuronal development. As given in Figure $1 b$, all $\mathrm{Kv} 1$ channels were absent at postnatal day 2 (only shown for Kv1.1) and Kv1.2-Kv1.6 were even not expressed at postnatal day 6 . Kv1.1 was the earliest channel to be detected in some granule cells of the dentate gyrus and in some pyramidal neurons of CA3. Thus, all Kv1 channels are less expressed or 
Figure 3. Presence of Kv1.4 in axons of cultivated granule cells mirrors its occurrence in adult mossy fibers in vivo. Hippocampal neurons cultivated for $18 \mathrm{~d}$ (18 DIV) were incubated with the antisera against Kv1.4. A granule cell $(G)$ characterized by its smaller and more globular perikaryon compared with pyramidal neurons is shown in $A$. Besides the somatodendritic compartment, the axon $(a x)$ with its branching collaterals is also stained. $B$ gives a detail of the hippocampal CA3 area. The granule cell-derived mossy fibers $(m f)$ contacting proximal dendrites of pyramidal neurons (stratum pyramidale, $s p$ ) contain high amounts of Kv1.4 $\alpha$-subunit. Scale bars: $A, 20 \mu \mathrm{m} ; B, 250 \mu \mathrm{m}$.

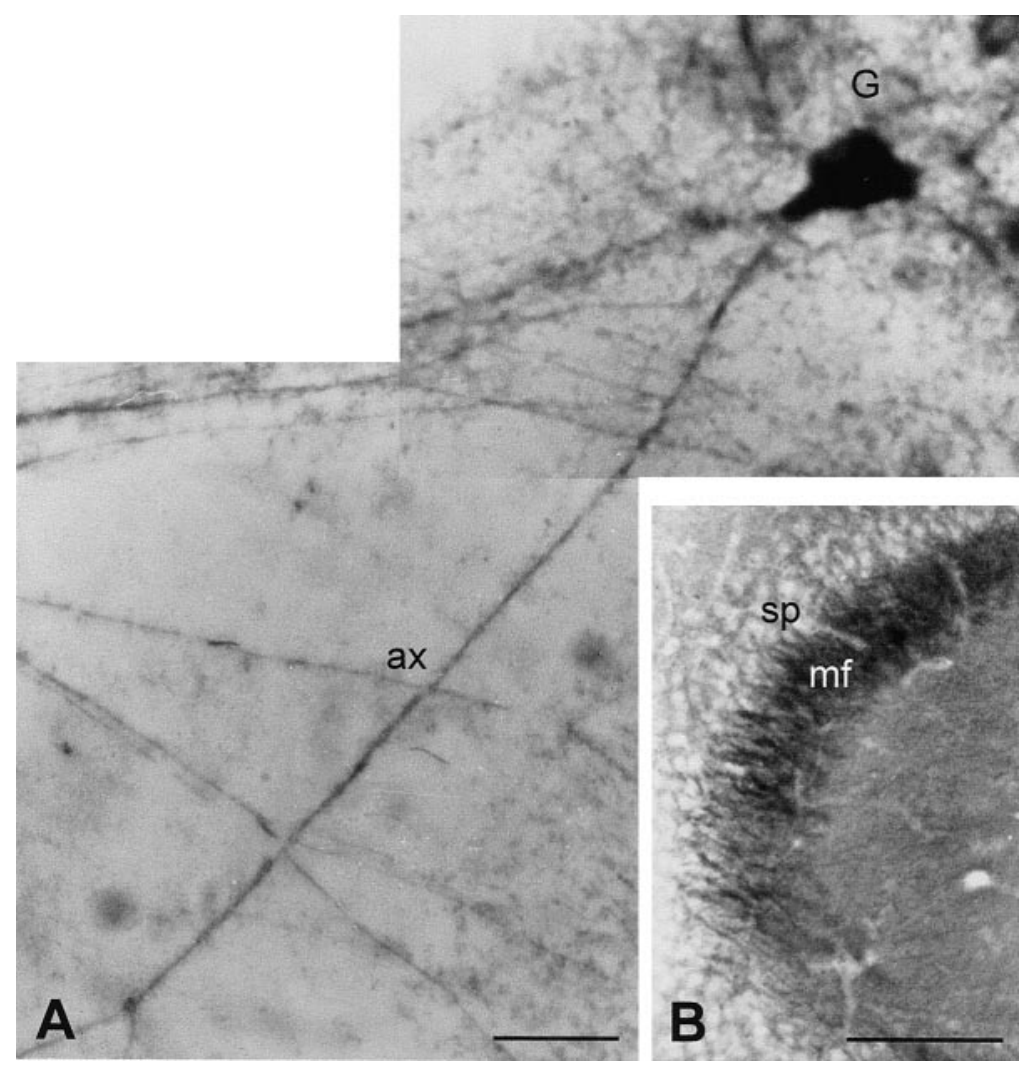

Table 1. Expression of Kv1.1-Kv1.6 channel subunits in different types of neurons in hippocampal cultures during in vitro development

\begin{tabular}{|c|c|c|c|c|c|c|}
\hline \multirow[b]{2}{*}{ IC with anti- } & \multicolumn{2}{|c|}{ 10-12 DIV } & \multicolumn{2}{|c|}{ 12-14 DIV } & \multicolumn{2}{|c|}{$16-20 \mathrm{DIV}$} \\
\hline & $\mathrm{P}$ & $\mathrm{G}$ & $\mathrm{P}$ & G & $\mathrm{P}$ & G \\
\hline Kv1.1 & $\mathrm{x}$ & $\mathrm{x}$ & $\mathrm{x}$ & $\mathrm{x}$ & $\mathrm{x}$ & $\mathrm{x}$ \\
\hline $\mathrm{Kv} 1.2$ & - & - & $\mathrm{x}$ & - & $\mathrm{x}$ & $\mathrm{x}$ \\
\hline Kv1.3 & - & - & $\mathrm{x}$ & $\mathrm{x}$ & $\mathrm{x}$ & $\mathrm{x}$ \\
\hline Kv1.4 & - & - & 一 & - & $\mathrm{x}$ & $\mathrm{x}$ \\
\hline Kv1.5 & - & - & $\mathrm{x}$ & $\mathrm{x}$ & $\mathrm{x}$ & $\mathrm{x}$ \\
\hline Kv1.6 & - & - & $\mathrm{x}$ & $\mathrm{x}$ & $\mathrm{x}$ & $\mathrm{x}$ \\
\hline
\end{tabular}

Hippocampal neurons cultivated for the days indicated (DIV) were incubated with the antisera against Kv1.1-Kv1.6 as given in Materials and Methods. P denotes pyramidal neurons distinguished by the large pyramidal morphology and $G$ denotes granule cells, which are smaller and more globular in shape. Note that Kv1.1 is the first channel to be expressed in both pyramidal neurons, as well as granule cells. $\mathrm{Kv} 1.2$ is first detected in pyramidal neurons at $12 \mathrm{DIV}$ and later at $16 \mathrm{DIV}$ in granule cells. Kv1.3, Kv1.5, and Kv1.6 show up at 12 DIV in both types of neuron. Expression of Kv1.4 can not be observed before 16 DIV. These developmental differences between the two types of neurons have been observed in at least three different preparations.

almost absent from hippocampal CA areas and the dentate gyrus $(D G)$ at postnatal day $2(\mathrm{Kv} 1.1-\mathrm{Kv} 1.6)$ or postnatal day 6 (Kv1.2Kv1.6). This late postnatal occurrence parallels that described for Kv1.4 and Kv1.5 in rat (Maletic-Savatic et al., 1995).

\section{Developmental, neuron type, and subcellular distribution of Kv1 channel $\alpha$-subunits in primary culture of mouse hippocampus}

To gain more insight into the developmental expression and differential subcellular distribution, we used mouse hippocampal primary cultures, which are more suitable for experimental manipulations. Hippocampal neurons cultivated for $18 \mathrm{~d}$ expressed all Kv1 channel subunits, which could be clearly detected in perikarya and processes of pyramidal neurons and granule cells (Fig. 2, large panels). In contrast, after $6 \mathrm{~d}$ in culture, none of the Kv1 channel subunits could be found (Fig. 2, insets). Closer inspections revealed that, besides their occurrence in somatodendritic compartments, Kv1.1, Kv1.2, and Kv1.6 were also found in axons mostly belonging to pyramidal neurons (Fig. 2, arrowheads). In pyramidal neurons of 18 DIV obtained from 10 different preparations, these channels were generally found in axonal and somatodendritic compartments, whereas Kv1.3, Kv1.4, and Kv1.5 were restricted to somatodendritic compartments. Thus, the observed subcellular distribution in culture exactly reflects the in situ situation in adult hippocampal pyramidal neurons.

After prolonged cultivation, discernible granule cells developed in our culture system. These neurons are characterized by their smaller size and more globular shape, few thin dendrites, and a long multiply branching axon when compared with pyramidal neurons (Große et al., 1998). Kv1.4 was indeed found in axonal processes of granule cells after 3 weeks in culture (Fig. $3 A$ ), as could be expected from its in situ localization (Figs. $1 a, E, 3 B$ ). The other Kv1 channel subunits also occurred in granule cells. They were expressed sometimes later during development when compared with pyramidal neurons as seen for Kv1.2 (Table 1).

Differences in the neuron type specificity and subcellular distribution of Kv1 channel $\alpha$-subunits between adult hippocampus and primary hippocampal cultures are outlined in Table 2. For pyramidal neurons, these differences were mainly found in the perikaryal distribution of the various Kv1 channel subunits. A perikaryal localization is mostly absent in vivo and retained in culture probably because cultured neurons lack topographically and functionally defined inputs, which may enhance sorting to the dendritic or axonal compartment. Greater differences were found when regarding granular cells in vivo and in culture. Whereas 
Table 2. Similarities and differences between the cellular and subcellular distribution of Kv1 $\alpha$-channel subunits in hippocampus in vivo and in primary cultures

\begin{tabular}{|c|c|c|c|c|c|c|c|c|c|c|c|c|}
\hline & \multicolumn{6}{|c|}{ Pyramidal neurons } & \multicolumn{6}{|c|}{ Granule cells } \\
\hline & \multicolumn{3}{|c|}{$\mathrm{CA} 1-\mathrm{CA} 3$} & \multicolumn{3}{|c|}{ Primary culture } & \multicolumn{3}{|c|}{ Dentate gyrus } & \multicolumn{3}{|c|}{ Primary culture } \\
\hline & per & ax & den & per & $\mathrm{ax}$ & den & per & $\mathrm{ax}$ & den & per & $\mathrm{ax}$ & den \\
\hline Kv1.1 & + & + & + & + & + & + & + & + & + & + & - & + \\
\hline $\mathrm{Kv} 1.2$ & - & + & + & + & + & + & - & $(+)$ & + & + & + & + \\
\hline $\mathrm{Kv} 1.3$ & + & - & + & + & - & + & + & $(+)$ & + & + & - & + \\
\hline $\mathrm{Kv} 1.4$ & - & - & + & + & - & + & - & + & + & + & + & + \\
\hline $\mathrm{Kv} 1.5$ & - & - & + & + & - & + & - & $(+)$ & + & + & - & + \\
\hline Kv1.6 & - & + & + & + & + & + & - & $(+)$ & + & + & - & + \\
\hline
\end{tabular}

Subcellular distributions of the Kv1.1-Kv1.6 potassium $\alpha$-channel subunits in perikarya (per), axons (ax), or dendrites (den) of pyramidal neurons in adult hippocampal CA1-CA3 or of hippocampal pyramidal neurons grown in cultures for 3 weeks are compared on the left part of the table. Note that the axonal versus dendritic distribution of all Kv1 channels is identical in vivo and in culture. The perikaryal distribution of all Kv1 channels shown in culture is not observed for Kv1.2 and Kv1.4-Kv1.6 in vivo. Probably pyramidal neurons might reach a less differentiated stage in cell culture in which functionally and topographically defined inputs are lacking. A greater difference with respect to the subcellular distribution is seen when comparing granule cells of adult dentate gyrus with those in primary culture (right part of the table). Whereas the dendritic occurrence is similar in either environment, an axonal localization is difficult to ascertain in vivo for Kv1.2, Kv1.3, Kv1.5, and Kv1.6 (see Fig. 1a) but is clearly seen in culture for Kv1.2 and Kv1.4 and absent for Kv1.3, Kv1.5, and Kv1.6. The axonal localization of Kv1.1 observed in vivo may depend on the input from axons of the entorhinal cortex. This input is lacking in culture, probably explaining why in cultured granule cells Kv1.1 is not associated with axons (compare Fig. $1 a, A$ with Fig. 2).
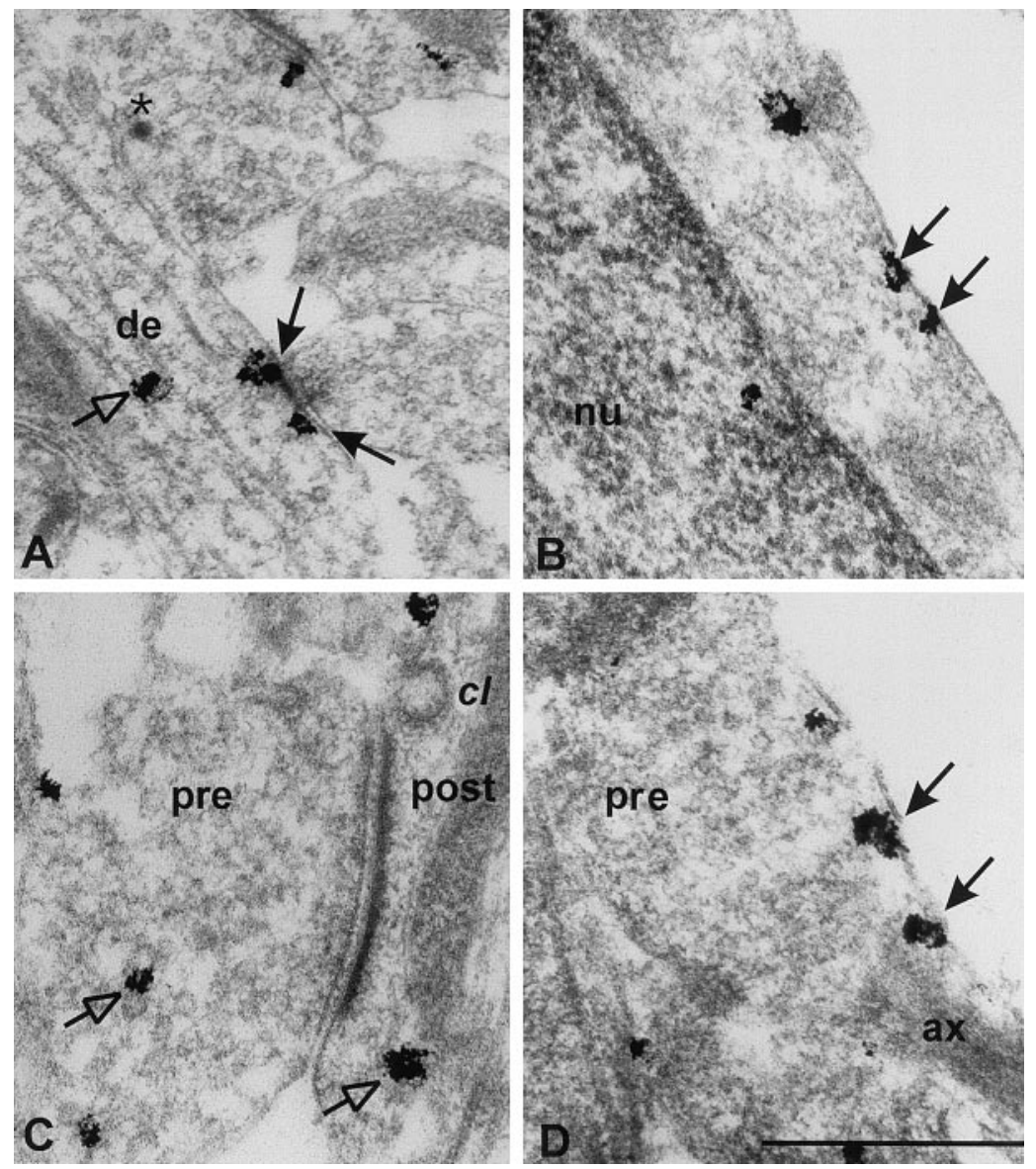

Figure 4. Immune electron microscopic subcellular localization of Kv1.2 in hippocampal neurons. Hippocampal neurons (15 DIV) were processed for electron microscopy as described in Materials and Methods. Immunoreactive staining can be detected at the plasma membrane ( filled arrows) of a dendrite $(d e)(A)$, an axon $(a x)$ with the ending presynaptic (pre) terminal $(D)$, and the perikaryon $(B)$. In addition, Kv1.2 $\alpha$-subunit is found to be localized in vesicular structures (open arrows) in presynaptic and postsynaptic $(C)$ areas and in dendrites $(A)$. Rarely, large dense core vesicles (asterisk in $A$ ) and clathrin-coated vesicles ( $c l$ in $C$ ) were observed. Scale bar: $A$, $0.9 \mu \mathrm{m} ; B-D, 0.5 \mu \mathrm{m}$. dendritic localization appeared to be similar under either condition, axonal localization was sometimes difficult to ascertain in vivo (Kv1.2, Kv1.3, Kv1.5, Kv1.6). In culture, a clear-cut axonal localization in granule cells was only found for Kv1.2 and Kv1.4, the latter being expressed also in mossy fibers in vivo. The failure of an axonal localization of Kv1.1 in culture may be attributable to the lack of inputs from the entorhinal cortex not present in our hippocampal cultures.

\section{Electron microscopic analysis of the subcellular distribution of Kv1.2}

The axonal and somatodendritic localization of Kv1.2 in cultivated hippocampal neurons was further analyzed by electron microscopy using a preembedding approach. As expected, we detected Kv1.2 at the plasma membrane of the perikaryon, of dendrites, and of synapses (Fig. 4A,B,D). We also found Kv1.2 in the endoplasmic reticulum (data not shown) in which protein 
Table 3. Developmental increase in $\mathrm{K}^{+}$currents in hippocampal neurons

\begin{tabular}{|c|c|c|c|c|}
\hline & \multicolumn{2}{|c|}{ 9-11 (9.6 \pm 0.2 DIV $)$} & \multicolumn{2}{|c|}{$15-24(16.6 \pm 3$ DIV $)$} \\
\hline & Control & $0.5 \mathrm{~mm} 4-\mathrm{AP}$ & Control & $0.5 \mathrm{~mm} 4-\mathrm{AP}$ \\
\hline \multirow{3}{*}{ Total $\mathrm{K}^{+}(\mathrm{A}+\mathrm{K})$ current } & $46.3 \pm 8.6$ & $39.7 / 20.1$ & $310 \pm 43$ & $211 \pm 43.3$ \\
\hline & $\mathrm{pA} / \mathrm{pC}(n=11)$ & $\mathrm{pA} / \mathrm{pC}(n=2)$ & $\mathrm{pA} / \mathrm{pC}(n=8)$ & $\mathrm{pA} / \mathrm{pC}(n=8)$ \\
\hline & $14.4 \pm 3.3$ & $2.9 / 2.6$ & $117 \pm 33.6$ & $50.6 \pm 23.7$ \\
\hline Isolated $\mathrm{K}^{+}$current & $\mathrm{pA} / \mathrm{pC}(n=10)$ & $\mathrm{pA} / \mathrm{pC}(n=2)$ & $\mathrm{pA} / \mathrm{pC}(n=8)$ & $\mathrm{pA} / \mathrm{pC}(n=8)$ \\
\hline
\end{tabular}

Hippocampal neurons cultivated for the days indicated (DIV) before they were analyzed for $\mathrm{K}^{+}$currents in the absence or presence of 4-AP. Cultures from different preparations were used; the mean DIV are given in parentheses. The number $(n)$ of neurons analyzed for each parameter is given in parentheses. The age-dependent differences are statistically significant $\left(I_{\max }, p=0.0004\right.$ and $\left.I_{\mathrm{K}}, p=0.0005\right)$ according to the Wilcoxon test for independent spot checks. Values represent the mean \pm SEM.
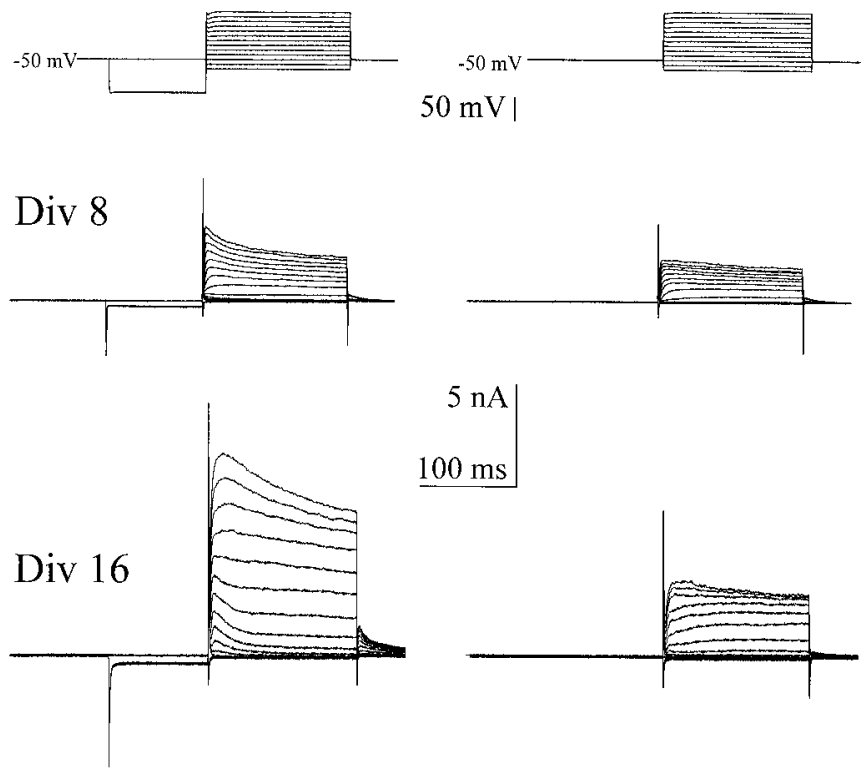

\section{$5 \mathrm{nA}$
$100 \mathrm{~ms}$}

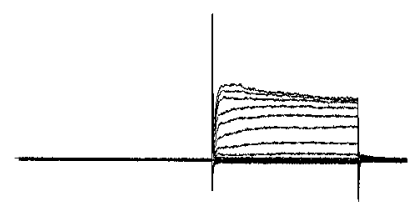

Figure 5. Developmental increase in $\mathrm{K}^{+}$currents in hippocampal neurons. Left traces show superimposed series of currents after voltage jumps (top panels) from -70 to $+50 \mathrm{mV}(150 \mathrm{msec})$ with a preceding hyperpolarization to $-120 \mathrm{mV}(100 \mathrm{msec})$. Current responses show a transient $\left(I_{\mathrm{A}}\right)$ and a sustained $\left(I_{\mathrm{K}}\right)$ component in a cell at 8 DIV (middle), as well as in a more mature cell at 16 DIV. Right traces show similar voltage steps without a hyperpolarizing prepulse, which isolates the sustained $I_{\mathrm{K}}$. In the younger cell, maximal total outward current was $3317 \mathrm{pA}$ and $I_{\mathrm{K}}$ was 1753 $\mathrm{pA}$, whereas at 16 DIV total current amplitude was $9292 \mathrm{pA}$ and $I_{\mathrm{K}}$ was 2986 pA.

synthesis occurs. In primary neuronal cultures, an axonal localization expected from the light microscopic analysis (Fig. 2) could be ascertained at the electron microscopic level only if the terminating synaptic bouton was clearly identified, as seen in Figure 4 D. Kv1.2-containing vesicles were observed in addition in dendrites (Fig. 4A) and also in synapses (Fig. 4C). They probably represent transport vesicles for the Kv1.2 channel subunit on their way to the final destination in the somatodendritic and/or synaptic compartment in which they fuse with the plasma membrane thereby translocating an active channel.

\section{$\mathrm{K}^{+}$currents and secretion in developing hippocampal neurons}

The developmental expression of the Kv1 channels in our culture system was functionally analyzed using two different experimental approaches. First, $\mathrm{K}^{+}$currents in old cultures (16.6 \pm 3 DIV) were compared with less differentiated $(9.6 \pm 0.2$ DIV) cells (Table 3). At both stages, a transient A-type and a sustained
K-type outward current could be elicited by positive voltage steps. However, the amplitude of these voltage-gated $\mathrm{K}^{+}$currents dramatically increased during prolonged cultivation (Fig. 5), which may be attributed to the increasing expression of Kv1 channel subunits.

Although the developmental increase in normalized current is well consistent with the immunocytochemical data, the early transient component in the younger group of neurons must be explained by subunits from other Kv channel subfamilies. Indeed, this transient component was also seen in cultures at 4 DIV $(n=$ 4; data not shown) having not yet expressed Kv1 channels (Fig. 2).

In a second approach, stimulated $\left[{ }^{3} \mathrm{H}\right] \mathrm{GABA}$ release was measured using 4-AP as a secretagogue. 4-AP has been shown to preferentially block $\mathrm{K}^{+}$channels, including those of the Kv1 family, thereby depolarizing the plasma membrane, which finally leads to an opening of voltage-dependent $\mathrm{Ca}^{2+}$ channels followed by secretion. 4-AP stimulated $\left[{ }^{3} \mathrm{H}\right] \mathrm{GABA}$ release from neurons cultivated for $21 \mathrm{~d}$ and increased the stimulatory effect of $25 \mathrm{mM} \mathrm{K}^{+}$. In contrast, younger cultures (7 DIV) did not secrete after application of 4-AP, whereas they could be stimulated by elevating the free $\mathrm{K}^{+}$-concentration to $25 \mathrm{~mm}$ (Table 4).

These functional data support the morphological evidence for a large increase in functional $\mathrm{Kv} 1$-based $\mathrm{K}^{+}$channel density in hippocampal neurons during the third postnatal week.

\section{Expression of Kv1.1, Kv1.2, and Kv1.4 depends on secretory activity}

As shown above, the developmental pattern of Kv1 subunits in cultured hippocampal neurons resembles the in situ situation to a large extent. We therefore used the culture system to study mechanisms that might regulate the expression of $\mathrm{Kv}$ channels.

The vesicular localization of Kv1.2 detected at the electron microscopic level suggests that the functional expression of these channels involves vesicular sorting with a final fusion event by which the channels are integrated into the plasma membrane. Membrane fusion requires the concerted interaction of highly conserved proteins, including synaptobrevins, syntaxins, and SNAP-25. Clostridial neurotoxins, such as tetanus toxin and the botulinum toxins A-F, are excellent tools to block regulated and constitutive fusion processes by cleaving the key proteins synaptobrevin (TeNt, BoNt/B), syntaxin, and SNAP-25 (BoNt/A), respectively (Ahnert-Hilger and Bigalke, 1995).

In neurons treated at $13 \mathrm{DIV}$ with either TeNt or BoNt/A, the expression of Kv1.1, Kv1.2, and Kv1.4 dramatically declined or disappeared $5 \mathrm{~d}$ later (Fig. 6, third and fourth rows), whereas the expression of Kv1.6 (Fig. 6, first row), as well as Kv1.3 and Kv1.5 (data not shown), was unaffected. For Kv1.1 and Kv1.2, some residual immunoreactivity could be detected in either the somatodendritic or axonal (arrows) compartment after toxin treat- 

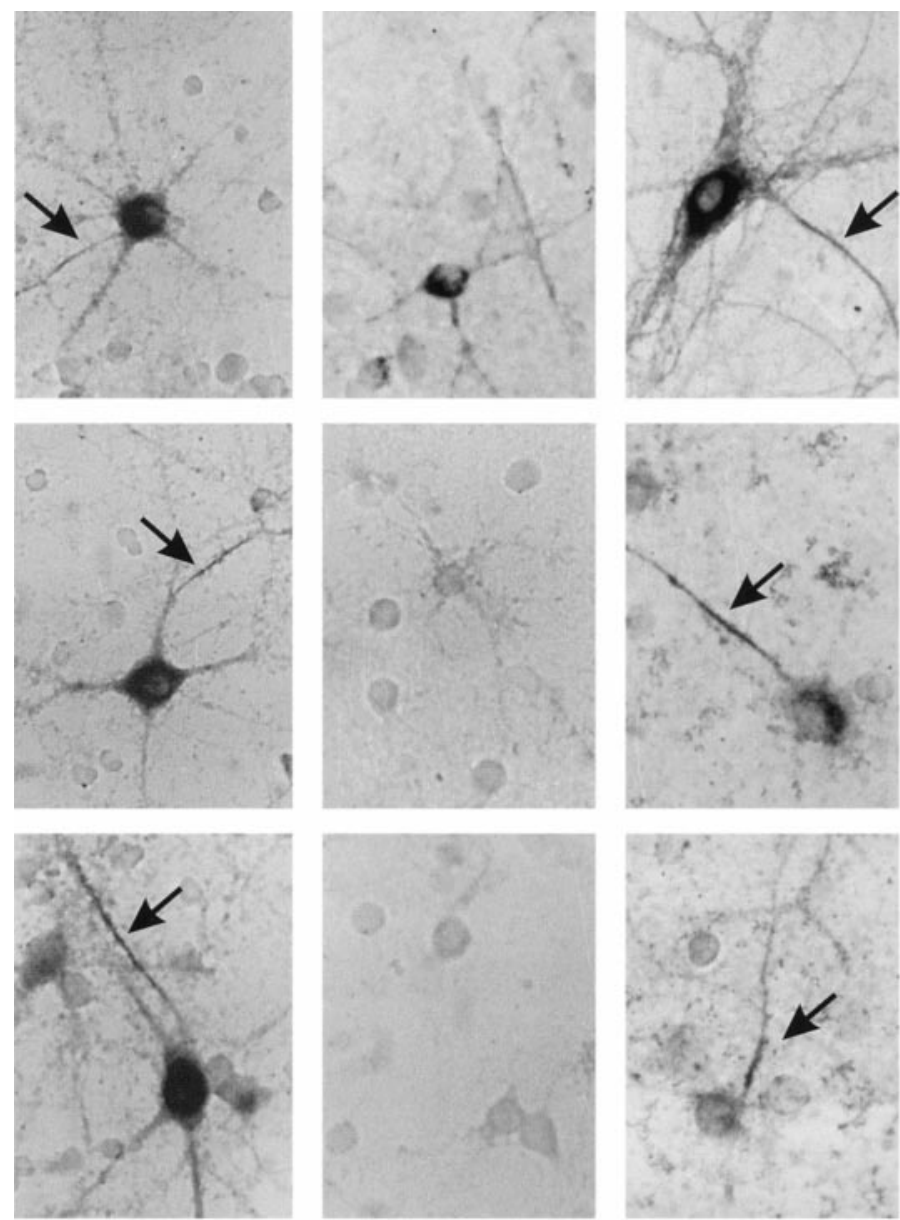

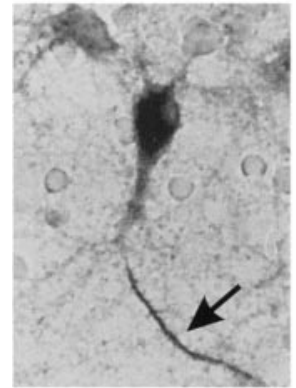

Kv1.6

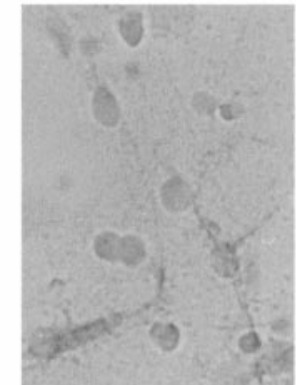

Kv1.4
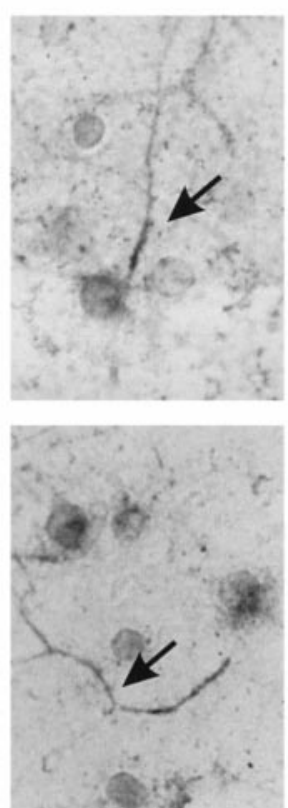

Kv1.2
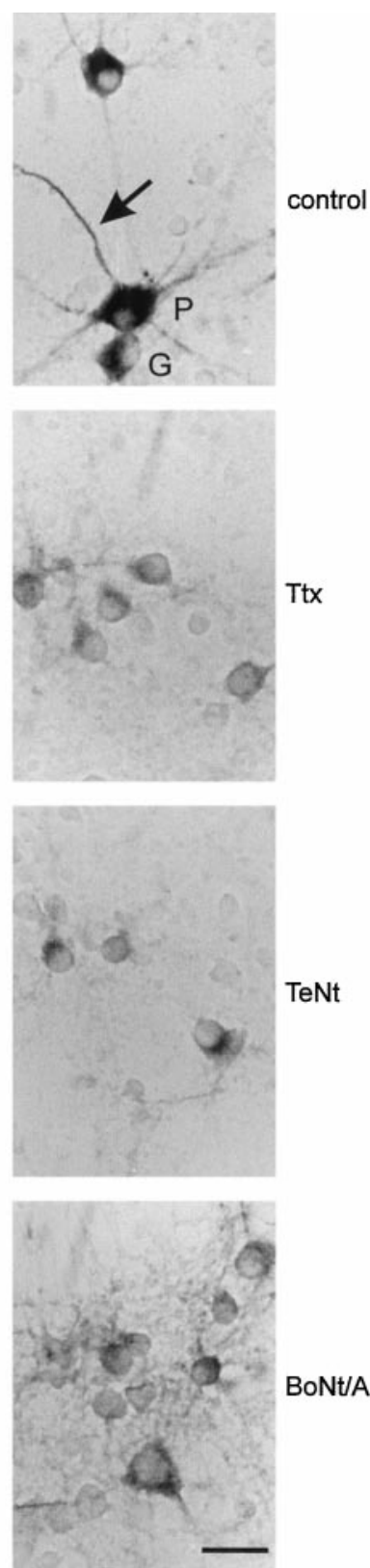

Kv1.1
Figure 6. Expression of Kv1.1-Kv1.6 channels is differentially downregulated by toxins impairing synaptic activity. Hippocampal neurons received solvent (control), tetrodotoxin (Ttx; $1 \mu \mathrm{M})$, tetanus toxin $(T e N t ; 1 \mathrm{~nm})$, or botulinum $\mathrm{A}$ toxin $(B o N t / A ; 20 \mathrm{nM})$ at $13 \mathrm{DIV}$ as indicated on the right. Neurons were fixed $5 \mathrm{~d}$ later and processed for immunocytochemistry using the Kv1 antisera indicated below each row of panels. The arrows denote the axonal staining observed with the antisera against Kv1.6, $\mathrm{Kv1.2}$, and Kv1.1. Note the complete disappearance of Kv1.4 and the reduced levels of Kv1.1 and Kv1.2 channel proteins in toxin-treated neurons, whereas the expression of Kv1.6 channel subunit remained unchanged. Comparable data were obtained in at least three different experiments. Scale bar, $20 \mu \mathrm{m}$. ment, but no staining was found in toxin-treated cultures analyzed for Kv1.4. The axonal localization of Kv1.1 and Kv1.2 and its sensitivity to toxin treatment was further analyzed by double immunolabeling using the dendritic marker MAP2. As can be clearly seen in Figure 7, the antibody against MAP2 stained all dendrites, leaving the axons unlabeled. These axons were, however, clearly stained when using antisera against Kv1.1 (Fig. 7, top panels) or Kv1.2 (Fig. 7, bottom panels), respectively. Pretreatment of the cultures with BoNT/A at 13 DIV drastically diminished the protein expression in axons and dendrites for Kv1.1 and Kv1.2, leaving MAP2 expression unchanged.

The observed changes in Kv1 channel expression could be attributable to either impaired fusion of transport vesicles containing the channel subunits or reduced synaptic activity in the neuronal network, which also depends on exocytosis of transmitter-filled vesicles. To distinguish between these possibil- ities, we used TTX, which is known to inactivate fast sodium channels thereby preventing action potentials and synaptic activity. As can be seen in Figure 6 (second row), treatment with TTX also diminished the developmental expression of Kv1.1, Kv1.2, and $\mathrm{Kv1.4}$, whereas the other Kv1 channels remained unaffected.

The reduced expression of Kv1.1 and Kv1.2 was confirmed by immunoreplica analysis (Fig. 8). Treatment with BoNt/A and B, as well as with TeNt, resulted in cleavage of SNAP-25 or synaptobrevin, respectively, whereas treatment with TTX did not change these proteins. Comparable with what we have seen in the immunocytochemical analysis, all toxins decreased the amount of Kv1.1 and Kv1.2 (Fig. 6, top two rows). A completely different picture was obtained, however, when toxins were applied at 18 DIV. Although cleavage of the target proteins still was successful, the expression of Kv1.1 and Kv1.2 was no longer affected. These data indicate that the expression of Kv1.1, Kv1.2, and Kv1.4 only 

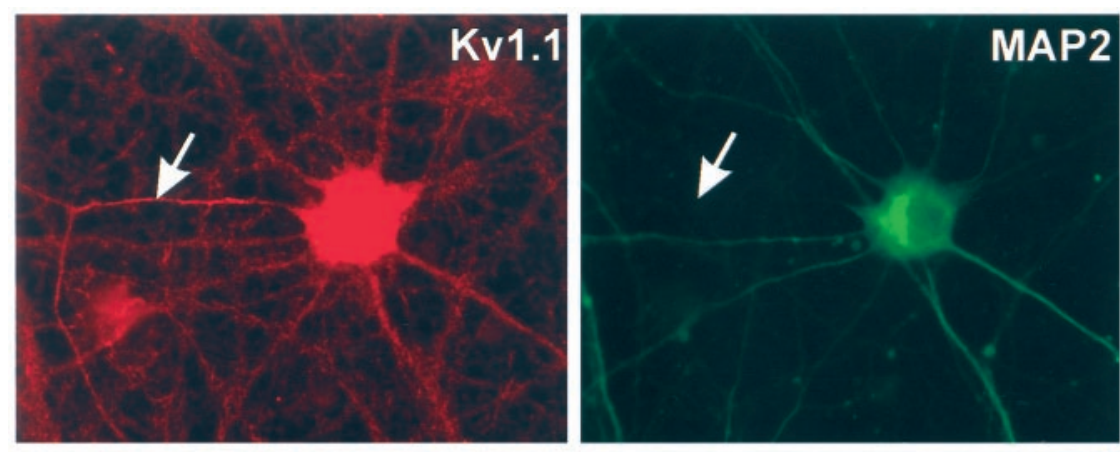

\section{control}
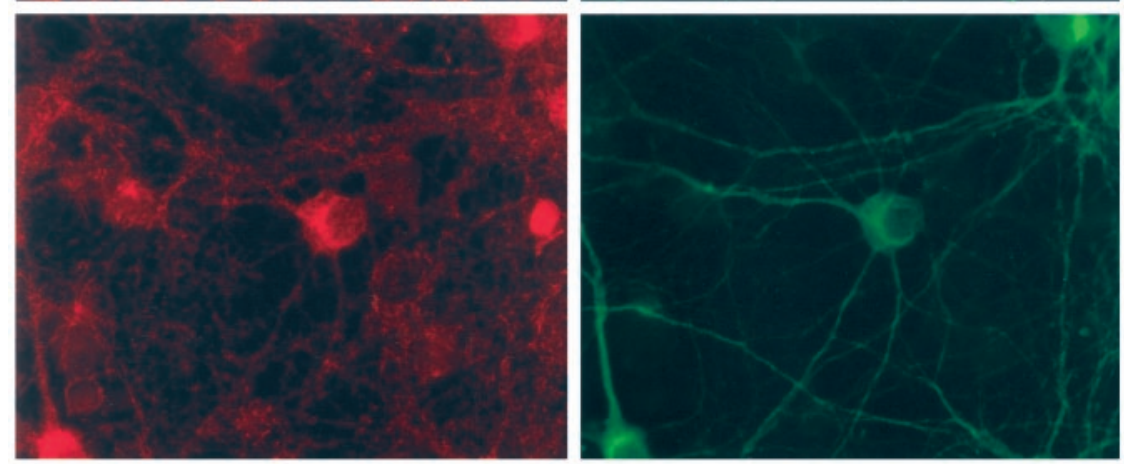

BoNt/A

Figure 7. Axonal localization of Kv1.1 and Kv1.2 and their disappearance after BoNt/A treatment. The protocol followed in principle the one outlined in Figure 5, but started at 7 DIV and lasted $11 \mathrm{~d}$ up to $18 \mathrm{DIV}$. After fixation neurons were double-labeled using the indicated antisera against Kv1.1 and Kv1.2 (red) and a monoclonal antibody against MAP2 (green). The arrows indicate axons that are only immunopositive for Kv1.1 (top panels) or Kv1.2, respectively, but exhibit no staining for the dendritic marker MAP2. Pretreatment with BoNt/A only impairs the expression of the Kv1 channel proteins but does not influence MAP2. The earlier application of BoNt/A (7 DIV) may explain why no residual immunoreactivity was found in axons (compare with Fig. 6, last row)
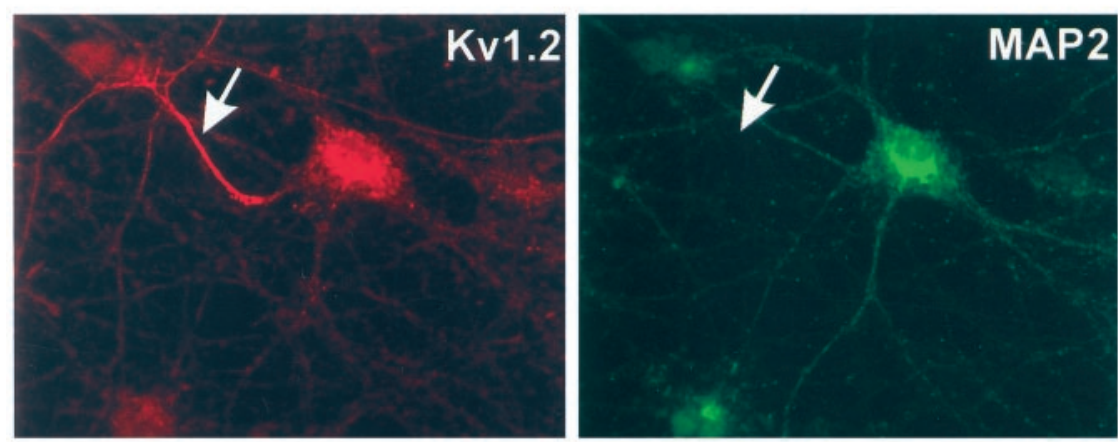

control
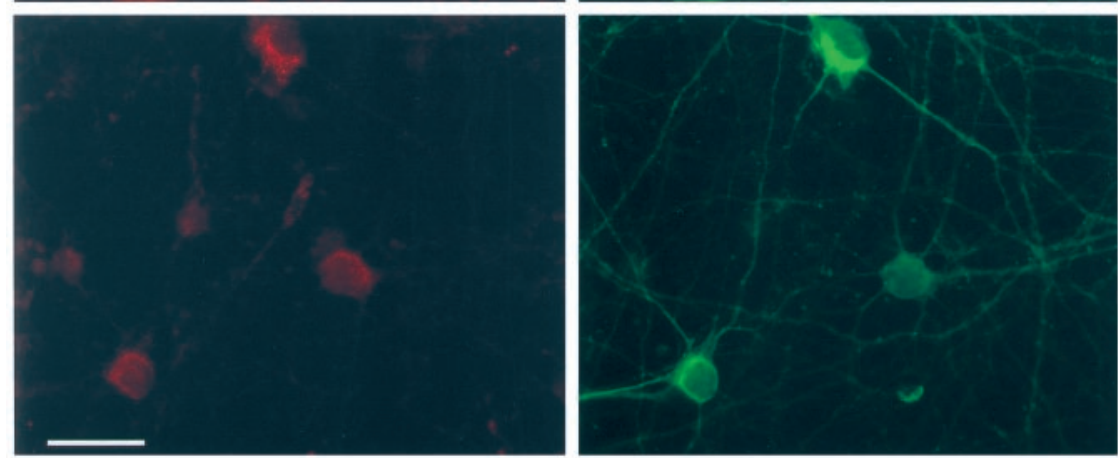

BoNt/A

depends on neuronal activity during a critical period in ontogenesis. In contrast, the expression of Kv1.3, Kv1.5, or Kv1.6 proved to be resistant to the various toxin treatments (Fig. $8 C$, bottom three panels), even when the cultures were treated with toxins for $13 \mathrm{~d}$ starting at 5 DIV (data not shown). The decline of Kv1.4 was difficult to analyze biochemically, because this channel subunit also occurs in cultured astroglial cells. Thus, when detecting Kv1.4 by immunoreplica analysis, no decrease in protein amount was discernible, although neurons no longer expressed Kv1.4 (Fig. 9).

Thus, clostridial neurotoxins, as well as TTX, dramatically decreases the expression of three members of the Kv1 family,
Kv1.1, Kv1.2, and Kv1.4. The decrease in the protein expression must be attributed to the absence of neuronal activity more than to a direct inhibition of constitutive fusion events by clostridial neurotoxins. In contrast, the expression and the sorting of Kv1.3, Kv1.5, and Kv1.6 appeared not to depend on synaptic activity and is developmentally regulated by an activity-independent program.

\section{DISCUSSION}

In the present study, protein expression of members of the Kv1 subfamily was followed in hippocampal primary cultures and compared with the in situ situation. After $2 \mathrm{~d}$ of postnatal devel- 


\section{DIV + 5DIV toxin}

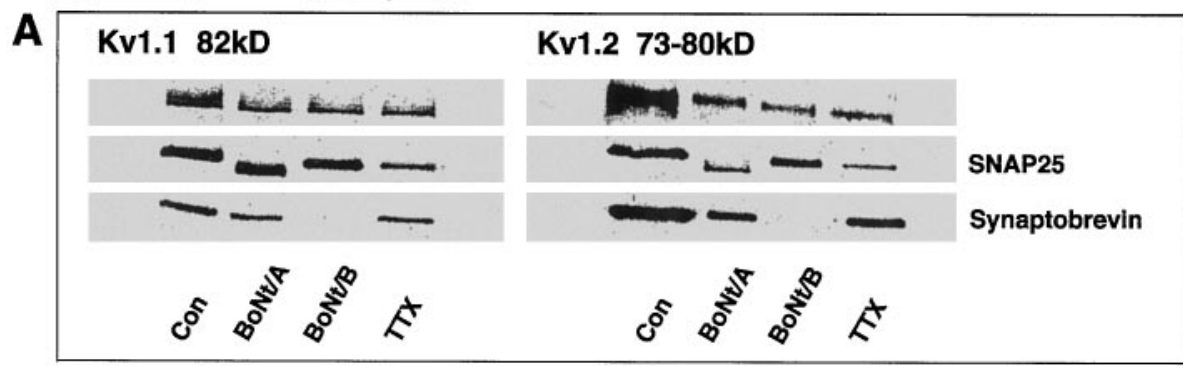

18DIV + 5DIV toxin

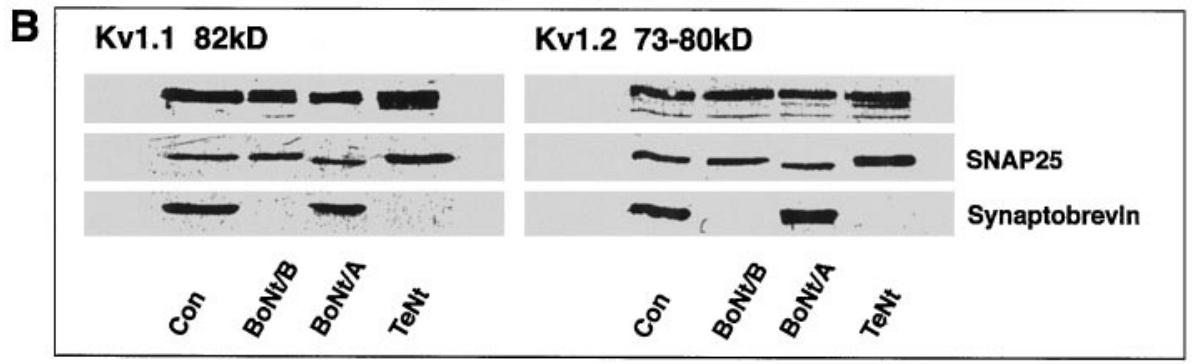

13DIV + 5DIV toxin

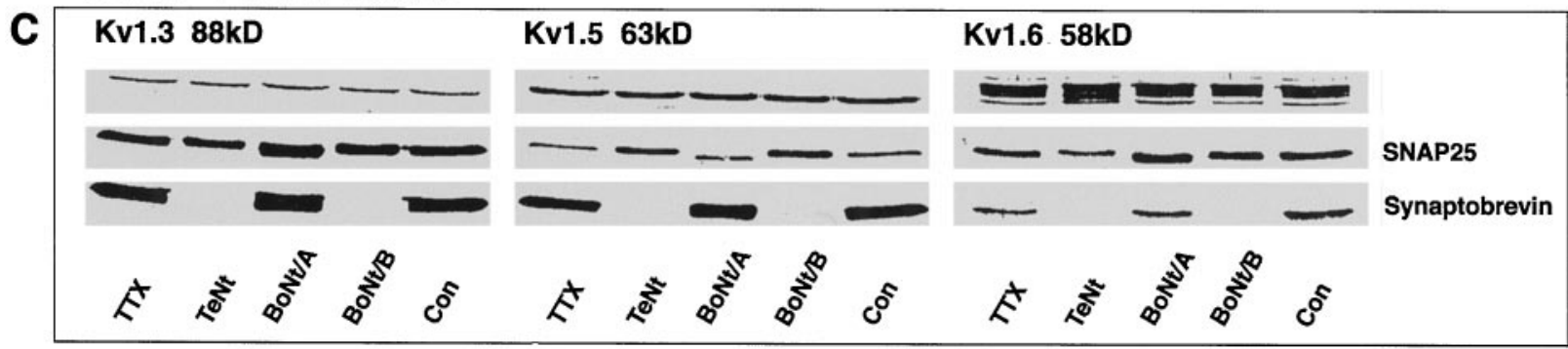

Figure 8. Immunoreplica analysis of control and toxin-treated hippocampal primary cultures. Hippocampal neurons were poisoned at $13(A)$ or $18(B)$ DIV with the following toxins: TTX $1 \mu \mathrm{M}$, TeNt $1 \mathrm{~nm}, \mathrm{BoNt} / \mathrm{A} 20 \mathrm{nM}$, and BoNt/B $20 \mathrm{~nm}$ as indicated. The cultures were harvested $5 \mathrm{~d}$ later and subjected to SDS-PAGE and immunoblotting using monoclonal antibodies against SNAP-25 and synaptobrevin, as well as antisera against the indicated Kv1 channel proteins. As expected, treatment with TeNt and BoNt/B completely abolished synaptobrevin and treatment with BoNt/A cleaved SNAP-25, whereas treatment with TTX did not change either of these proteins. Note that the amount of Kv1.1 and Kv1.2 channel protein was reduced in toxin-treated cultures and poisoned at 13 DIV $(A)$ but not at 18 DIV $(B)$, whereas Kv1.3, Kv1.5, and Kv1.6 $(C)$ remained unchanged irrespective of toxin treatment. Comparable data were obtained in at least three different experiments from different preparations of primary cultures.

opment, none of the Kv1 channels could be detected in brain sections in situ in the CA area. Kv1.1 was the first channel that appeared after $6 \mathrm{~d}$ in some pyramidal neurons. In both systems, expression of the proteins was dramatically upregulated during the second and third week of development, extending the recent observation that Kv1.4 and Kv1.5 are postnatally upregulated in the rat hippocampus (Maletic-Savatic et al., 1995). Besides the similar temporal pattern of expression in situ and in vitro, the cellular and subcellular distribution also run mostly in parallel in both systems. The two main types of excitatory hippocampal neurons, pyramidal neurons and granule cells, were discernible in culture and showed their typical occurrence of Kv1 channels. In contrast to what has been reported for the rat system (MaleticSavatic et al., 1995), we were able to show that Kv1.4, the only A-type channel subunit in this subfamily, appears in the axons of cultured granule cells that form the mossy fibers in adult hippocampus.

The upregulation of $\mathrm{Kv} 1$ channel expression is accompanied by a dramatic increase in the total $\mathrm{K}^{+}$current and an elevation of 4-AP-induced GABA secretion, indicating that the expressed channel subunits are functional in these cultivated neurons. Our data from cultured cells do not allow for a differential analysis of pyramidal cells and interneurons, which show marked differences in their expression pattern of $\mathrm{Kv}$ channel subunits in the hippocampus (Martina et al., 1998). Although Kv 1.4 was primarily absent in immature cultured cells and hippocampi, a transient outward current component was clearly discernible as early as 4 DIV. This transient is likely to be caused by the expression of other subunits from the Kv3 (Weiser et al., 1994) and Kv4 (Serodio and Rudy, 1998) subfamily. However, only few data are presently available regarding the developmental profile of these channel proteins in the hippocampus in which Kv4.2 appeared to be expressed as early as 6 DIV (Maletic-Savatic et al., 1995).

Clearly, GABA is mostly released from interneurons, although principal neurons might release lower amounts of the transmitter as well (Sloviter et al., 1996). Having seen that all Kv1 channels were completely absent in young cultures and clearly upregulated in all neurons after prolonged cultivation, GABA was used as a general parameter to test the neuronal secretory activity in our culture system. In this respect, it is worth mentioning that Kv1.1 is indeed present in CA1 interneurons, as revealed by single-cell reverse transcription-PCR (Martina et al., 1998). 

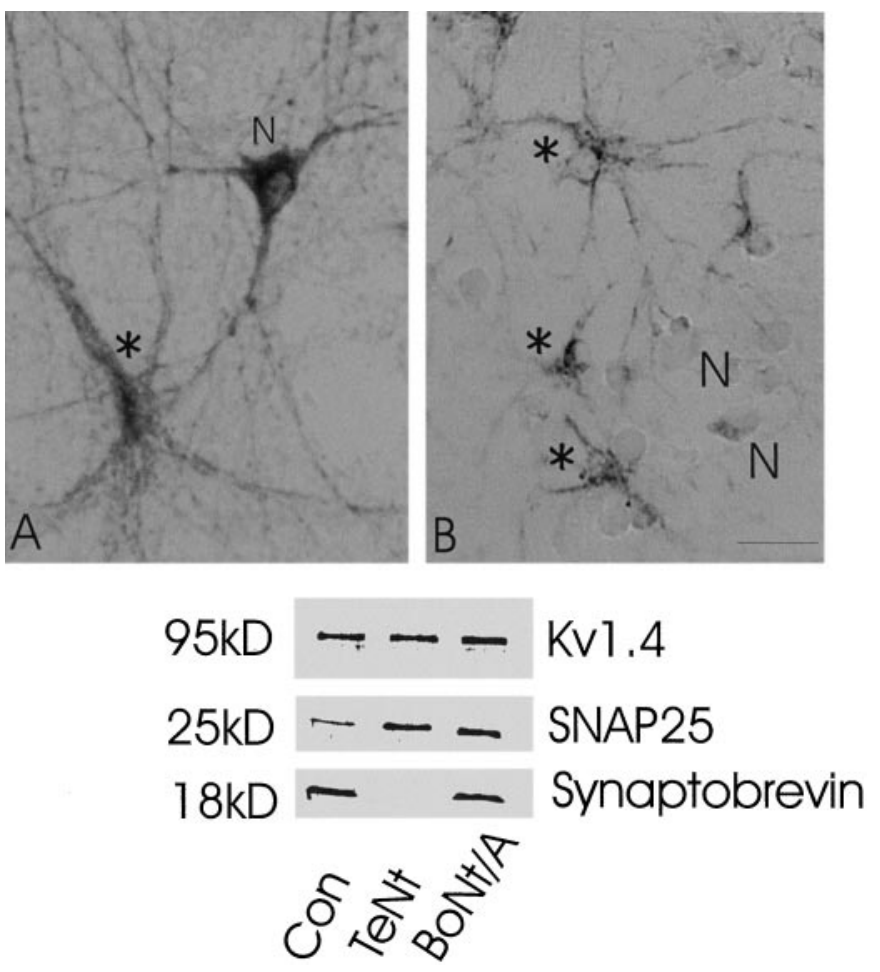

Figure 9. Differential localization of Kv1.4 in neurons and glial cells with or without toxin treatment. Hippocampal neurons received solvent (Con), tetanus toxin $(T e N t ; 1 \mathrm{nM})$, or botulinum A toxin $(B o N t / A ; 20 \mathrm{nM})$ at 13 DIV as given in Figure 6. Five days later, cultures were either fixed and processed for immunocytochemistry (top two panels) or harvested and subjected to SDS-PAGE and immunoblotting using the Kv1.4 antiserum or the antibodies against SNAP-25 or synaptobrevin as indicated. Although synaptobrevin and SNAP-25 are clearly cleaved by the respective toxin, no reduction in the total protein content of Kv1.4 can be observed. As revealed by the immunocytochemical analysis, Kv1.4 is only reduced in neurons $(N)$ but still present in glial cells, probably astrocytes (asterisks). Scale bar, $25 \mu \mathrm{m}$.

Cellular and subcellular distribution of Kv1 channels in our culture system appears to closely reflect the in situ situation that allows for the dissection of factors regulating their developmental upregulation. The vesicular localization of Kv1.2 at the electron microscopic level indicates that sorting and placing of the channels at the right position requires a fusion event. An association with putative transport vesicles has indeed been reported for Kv1.4 (Cooper et al., 1998) and for Kv2.1 (Du et al., 1998). Fusion events occur at synapses mediating chemical synaptic transmission but are also required for membrane and protein integration during outgrowth of neuronal processes. Especially SNAP-25 appears to be required for axon growth (Osen-Sand et al., 1993), and cleavage of this protein by BoNt/A has been shown very recently to reduce axonal and dendritic growth in cultivated hippocampal neurons (Große et al., 1999), whereas synaptobrevin did not interfere with the outgrowth of synaptic processes (Ahnert-Hilger et al., 1996). Although being highly toxic in individuals, these toxins appear to be not cytotoxic in vitro, just preventing the communication between neurons and their environment. Thus, besides inhibiting synaptic fusion, these toxins might also back up other types of transport vesicles responsible for the insertion of receptors or channels in the somatodendritic or axonal plasma membrane. By inhibiting neurotransmission, they also might influence indirectly the expression and/or trans-
Table 4. Contribution of potassium channels to regulated GABA secretion during development in culture

\begin{tabular}{lll} 
& \multicolumn{2}{l}{ Stimulated release (\% of control) } \\
\cline { 2 - 3 } & 7 DIV & $21 \mathrm{DIV}$ \\
\hline $0.5 \mathrm{mM}^{+}-\mathrm{AP}$ & $100 \pm 18$ & $250 \pm 22$ \\
$25 \mathrm{mM} \mathrm{K}^{+}$ & $181 \pm 20$ & $279 \pm 15$ \\
$25 \mathrm{mM} \mathrm{K}^{+} / 0.5 \mathrm{mM} \mathrm{4-AP}$ & $204 \pm 30$ & $303 \pm 23$
\end{tabular}

Hippocampal neurons cultivated for the days indicated (DIV) were preloaded with $\left[{ }^{3} \mathrm{H}\right] \mathrm{GABA}$ as given in Materials and Methods. Stimulation was performed by adding $0.5 \mathrm{~mm} 4-\mathrm{AP}$, by elevating the $\mathrm{K}^{+}$concentration to $25 \mathrm{~mm}$, or by applying 0.5 $\mathrm{mm} 4$-AP in the presence of $25 \mathrm{~mm} \mathrm{~K}{ }^{+}$. Secretion was stopped after $5 \mathrm{~min}$ at $37^{\circ} \mathrm{C}$. Radioactivity was analyzed in the supernatant and the lysate of cells. Release is calculated as percent of the amount of radioactivity present at the beginning of stimulation. Values are given as percent of control being $2.7 \pm 1$ and $3.4 \pm 1.2 \%$ in 7 or 21 DIV cultures, respectively, and represent the mean \pm SD of three individual cultures.

location of functional proteins at the plasma membrane. TeNt, BoNt/B, or BoNt/A inhibited the protein expression of Kv1.1, $\mathrm{Kv1.2}$, and Kv1.4, whereas the other Kv1 channel $\alpha$-subunits Kv1.3, Kv1.5, and Kv1.6 remained unaffected. To differentiate whether an impaired integration of the subunits into the plasma membrane or a reduced synaptic activity is responsible for the observed downregulation, we used tetrodotoxin to discriminate between these two possibilities. Tetrodotoxin, which reduces neuronal activity by blocking fast sodium channels, does not directly interfere with fusion events but indirectly prevents action potential-dependent $\mathrm{Ca}^{2+}$ transients, thereby interfering with $\mathrm{Ca}^{2+}$-dependent signal transduction pathways. As a result, synaptic transmission decreases. Comparable with what we have seen with clostridial neurotoxins, tetrodotoxin also downregulated the expression of Kv1.1, Kv1.2, and Kv1.4. Clostridial neurotoxins selectively interferes with exocytotic membrane fusion without directly affecting action potential-dependent $\mathrm{Ca}^{2+}$ transients, and tetrodotoxin directly affects $\mathrm{Na}^{+}$without directly interfering with membrane fusion, which however is blocked because of the lack of the $\mathrm{Ca}^{2+}$ transient. However, clostridial neurotoxins and tetrodotoxin behaved similarly in our model system in impairing secretion and reducing action potential-dependent events. Thus, reducing neuronal activity during a sensitive period between 13 and 18 DIV reduces expression of Kv1.1, Kv1.2, and Kv1.4 channel subunits. It cannot be ruled out, however, that clostridial neurotoxins in addition prevent fusion reactions required for the translocation of these channel subunits.

The Kv-channels that are sensitive to neuronal activity are diverse, comprising a fast inactivating A-type channel (Kv1.4) and two delayed rectifiers, one of which with very slow inactivation (Kv1.2). However, all three channel $\alpha$-subunits can coassemble to form heterotetramers, which have been reported for the combination of Kv1.1 with Kv1.2 (Christie et al., 1990; Isacoff et al., 1990; Ruppertsberg et al., 1990; Covarrubias et al., 1991; Wang et al., 1993) and of Kv1.2 with Kv1.4 (Sheng et al., 1993). Assembly of mixed channels should enable neurons to change their Kv1 channel make-up in response to altered synaptic inputs and thus may represent a form of neuronal plasticity. The critical period for the activity-dependent upregulation was approximately the beginning expression of Kv1 subunits. One of the activity-sensitive proteins, Kv1.1, appears to pioneer this process because it was the first being expressed in vivo and in our culture system. Interestingly, Kv1.1 knock-out mice exhibit enhanced excitability of the CA3 network, causing epilepsy in these animals 
(Smart et al., 1998). If Kv1.1 plays a role as a pacemaker in hippocampal pyramidal neurons, it could be speculated that its expression requires synaptic activity also from inhibitory GABAergic neurons. This would explain why Kv1.1 expression was prevented after treatment with the various toxins all inhibiting neuronal activity.

The toxin sensitivity of the expression of certain Kv1 channels suggests that neurotransmitters may be involved in their developmental upregulation. The regulation of A-type channels, i.e., Kv1.4, by neurotransmitters such as noradrenaline via a1adrenoceptors (Aghajanian, 1985) or acetylcholine via muscarinic receptors (Atkins et al., 1990) supports these ideas. However, in our hippocampal culture system, neither adrenergic nor cholinergic inputs are present, leaving GABA and glutamate as putative candidates. These amino acid transmitters acting via ionotropic, as well as metabotropic, receptors may trigger the expression of the respective Kv1 channels either directly or via release of neurotrophic factors. In a first attempt to address these questions, we applied selective antagonist of glutamatergic AMPA or NMDA receptors for several days during the critical period, which however failed to interfere with the expression of the sensitive Kv1 channels (our unpublished observation).

The expression of Kv1.1, Kv1.2, and Kv1.4 required neuronal activity only during a certain time window. Once expressed, neuronal activity no longer affected expression in our culture system. The factors and/or neurotransmitters involved in the sensitive period of expression, however, need to be determined. They may comprise neurotransmitters, as well as various neuromodulators, whose secretion could be either directly inhibited or depends on the proper release of a classical neurotransmitter.

Kv1.3, Kv1.5, and Kv1.6, although clearly absent at 6 DIV and developmentally upregulated, did not require any synaptic activity. Either these channels appear as part of an intrinsic program in the neurons or other factors are required for their upregulation, which however have to be released constitutively, not requiring membrane fusion.

Together, primary cultures of hippocampal neurons are suitable to study the developmental expression of Kv1 channels. Application of various toxins may help to dissect different principles involved in the developmental upregulation of Kv1 channels.

\section{REFERENCES}

Aghajanian GK (1985) Modulation of a transient outward current in serotonergic neurones by $\alpha_{1}$-adrenoceptors. Nature 315:501-503.

Ahnert-Hilger G, Bigalke H (1995) Molecular aspects of tetanus and botulinum neurotoxin poisoning. Prog Neurobiol 46:83-96.

Ahnert-Hilger G, Kutay U, Rapoport T, Wiedenmann B (1996) Synaptobrevin is essential for secretion but not for the outgrowth of synaptic processes. Eur J Cell Biol 70:1-11.

Atkins PT, Surmeier J, Kitai ST (1990) Muscarinic modulation of a transient $\mathrm{K}^{+}$conductance in rat neostriatal neurones. Nature 344:240-242.

Becher A, Drenckhahn A, Hähnlein I, Magittai M, Jahn R, AhnertHilger G (1999) The synaptophysin/synaptobrevin complex: a hallmark of synaptic vesicle maturation. J Neurosci 19:1922-1931.

Christie MJ, North RA, Osborne PB, Douglass J, Adelman JP (1990) Heteropolymeric potassium channels expressed in Xenopus oocytes from cloned subunits. Neuron 2:405-411.

Cooper EC, Milroy A, Jan YN, Jan LY, Lowenstein DH (1998) Presynaptic localization of Kv1.4-containing A-type potassium channels near excitatory synapses in the hippocampus. J Neurosci 18:965-974.
Covarrubias M, Wei A, Salkoff L (1991) Shaker, Shal, Shab, and Shaw express independent $\mathrm{K}^{+}$current systems. Neuron 7:763-773.

Du J, Tao-Cheng JH, Zerfas P, McBain CJ (1998) The $\mathrm{K}^{+}$channel, $\mathrm{Kv} 2.1$, is apposed to astrocytic processes and is associated with inhibitory postsynaptic membranes in hippocampal and cortical principal neurons and inhibitory interneurons. Neuroscience 84:37-48.

Ficker E, Heinemann U (1992) Slow and fast transient potassium currents in cultured rat hippocampal cells. J Physiol (Lond) 445:431-455.

Fletcher TL, DeCamilli P, Banker G (1994) Synaptogenesis in hippocampal cultures: evidence indicating that axons and dendrites become competent to form synapses at different stages of neuronal development. J Neurosci 14:6695-6706.

Gro $\beta$ e G, Tapp R, Wartenberg M, Sauer H, Fox PA, Grosse J, Gratzl M, Bergmann M (1998) Prenatal hippocampal granule cells in primary cell culture form mossy fiber boutons at pyramidal cell dendrites. J Neurosci Res 51:602-611.

Gro $\beta$ e G, Große J, Tapp R, Kuchinke J, Gorsleben M, Fetter I, HöhneZell B, Gratzl M, Bergmann M (1999) SNAP-25 requirement for dendritic growth of hippocampal neurons. J Neurosci Res 56:539-546.

Hamill OP, Marty A, Neher E, Sakmann B, Sigworth FJ (1981) Improved patch-clamp techniques for high-resolution current recording from cells and cell-free membrane patches. Pflügers Arch 391:85-100.

Hille B (1992) Ion channels of excitable membranes, Ed 2. Sunderland, MA: Sinauer.

Isacoff EY, Jan YN, Jan LY (1990) Evidence for the formation of heteromultimeric potassium channels in Xenopus oocytes. Nature 345:530-534.

Killisch I, Dotti CG, Laurie DJ, Luddens H, Seeburg PH (1991) Expression patterns of GABAA receptor subtypes in developing hippocampal neurons. Neuron 7:927-936.

Klee R, Ficker E, Heinemann U (1995) Comparison of voltagedependent potassium currents in rat pyramidal neurons acutely isolated from hippocampal regions CA1 and CA3. J Neurophysiol 74:1982-1995.

Laube G, Röper J, Pitt JC, Sewing S, Kistner U, Garner CC, Pongs O, Veh RW (1996) Ultrastructural localization of Shaker-related potassium channel-subunits and synapse-associated protein 90 to septate-like junctions in rat cerebellar Pinceaux. Mol Brain Res 42:51-61.

Maletic-Savatic M, Lenn NJ, Trimmer JS (1995) Differential spatiotemporal expression of $\mathrm{K}^{+}$channel polypeptides in rat hippocampal neurons developing in situ and in vitro. J Neurosci 15:3840-3851.

Martina M, Schultz JH, Ehmke H, Monyer H, Jonas P (1998) Functional and molecular differences between voltage-gated $\mathrm{K}^{+}$channels of fastspiking interneurons and pyramidal neurons of rat hippocampus. J Neurosci 18:8111-8125.

Osen-Sand A, Catsicas M, Staple JK, Jones KA, Ayala G, Knowles J, Grenningloh G, Catsicas S (1993) Inhibition of axonal growth by SNAP-25 antisense oligonucleotides in vitro and in vivo. Nature 364:445-448.

Rettig R, Wunder F, Stocker M, Lichtinghausen R, Mastiaux, Beckh S, Kues W, Pedarzani P, Schröter KH, Ruppersberg JP, Veh RW, Pongs O (1992) Characterization of a Shaw-related potassium channel family in rat brain. EMBO J 11:2473-2486.

Rhodes KJ, Keilbaugh SA, Barrezuata NX, Lopez KL, Trimmer JS (1995) Association and colocalization of $\mathrm{K}^{+}$channel $\alpha$ - and $\beta$-subunit polypeptides in rat brain. J Neurosci 15:5360-5371.

Rhodes KJ, Strassle BW, Monaghan MM, Bekele-Arcuri Z, Matos MF, Trimmer JS (1997) Association and colocalization of the Kvb1 and $\mathrm{Kvb} 2 \beta$-subunits with the $\mathrm{Kv} 1 \alpha$-subunits in mammalian brain $\mathrm{K}^{+}$ channel complexes. J Neurosci 17:8246-8258.

Robertson B (1997) The real life of voltage-gated $\mathrm{K}^{+}$channels: more than model behaviour. Trends Pharmacol Sci 18:474-483.

Roeper J, Pongs O (1996) Presynaptic potassium channels. Curr Opin Neurobiol 6:338-341.

Ruppertsberg JP, Schröter KH, Sakmann B, Stocker M, Sewing S, Pongs O (1990) Heteromultimeric channels formed by rat brain potassium channel proteins. Nature 345:535-537.

Salkoff L, Baker K, Butler A, Covarrubias M, Pak MD, Wei A (1992) An essential "set" of $\mathrm{K}^{+}$channels conserved in flies, mice and humans. Trends Neurosci 15:161-166.

Serodio P, Rudy B (1998) Differential expression of Kv4 $\mathrm{K}^{+}$channel subunits mediating subthreshold transient $\mathrm{K}^{+}$(A-type) current in rat brain. J Neurophysiol 79:1081-1091. 
Sheng M, Tsaur M-L, Jan YN, Jan LY (1992) Subcellular segregation of two A-type $\mathrm{K}^{+}$channel proteins in rat central neurons. Neuron 9:271-284.

Sheng M, Liao YJ, Jan YN, Jan LY (1993) Presynaptic A-current based on heteromultimeric $\mathrm{K}^{+}$channels detected in vivo. Nature 365:72-75.

Sloviter RS, Dichter MA, Rachinsky TL, Dean E, Goodman JH, Sollas AL, Martin DL (1996) Basal expression and induction of glutamate decarboxylase and GABA in excitatory granule cells of the rat and monkey hippocampal dentate gyrus. J Comp Neurol 373:593-618.

Smart SL, Lopantsev V, Zhang CL, Robbins CA, Wang H, Chiu SY, Schwartzkroin PA, Messing A, Tempel BL (1998) Deletion of the Kv1.1 potassium channel causes epilepsy in mice. Neuron 20:809-819. Veh RW, Lichtinghagen R, Sewing S, Wunder F, Grumbach IM, Pongs O
(1995) Immunocytochemical localization of five members of the Kv1 channel-subunits: contrasting subcellular locations and neuron-specific co-localizations in rat brain. Eur J Neurosci 7:2189-2205.

Wang H, Kunkel DD, Martin TM, Schwartzkroin PA, Tempel BL (1993) Heteromultimeric $\mathrm{K}^{+}$channels in terminal and juxtaparanodal regions of neurons Nature 365: 75-79.

Wang H, Kunkel DD, Schwartzkroin PA, Tempel BL (1994) Localization of Kv1.1 and Kv1.2, two K channel proteins, to synaptic terminals somata and dendrites in the mouse brain. J Neurosci 14:4588-4599.

Weiser M, Vega-Saenz-de-Miera E, Kentros C, Moreno H, Franzen L, Hillman D, Baker H, Rudy B (1994) Differential expression of Shawrelated $\mathrm{K}^{+}$channels in the rat central nervous system. J Neurosci 14:949-972. 